\title{
Las representaciones de estilo paleolítico en el conjunto de Domingo García (Segovia)
}

\author{
Sergio RiPoll LóPEZ * \\ Luciano José Municio González **
}

En febrero de 1992 se denunció la voladura de un panel con grabados rupestres en el término municipal de Domingo Garcia, en Segovia (fig. 1). Las acciones emprendidas a partir de este hecho, con el fin de determinar la localización exacta del total de las rocas grabadas, han dado lugar a la documentación de un importante conjunto de grabados inéditos de cronologia paleolitica, cuya presentación se realiza en las páginas siguientes. Los trabajos se han realizado en todo momento bajo los auspicios de la Junta de Castilla y León, amparados por un permiso de la Dirección General de Patrimonio y Promoción Cultural para la documentación de arte rupestre en esta comarca, expedido con carácter de urgencia debido al riesgo cierto que la proximidad de tres canteras de pizarra supone para las nuevas zonas con grabados.

El hallazgo de las primeras figuras se produjo de forma casual, al revisar el grabado de un caballo cuya existencia habiamos conocido por medio de una fotografia que nos mostró la Alcaldesa de Domingo Garcia, en la que era posible apreciar la silueta de un caballo de aspecto muy similar al del gran caballo de estilo paleolitico existente en este mismo núcleo artístico. El estudio directo de la figura, sin embargo, reveló una realización más o menos moderna de la misma, con un tratamiento de piqueteado fino, prácticamente sin pátina de envejecimiento, realizado con un instrumento puntiagudo y, probablemente, metálico.

* Profesor Titular del Departamento de Prehistoria e Historia Antigua de la Universidad Nacional de Educación a Distancia. c/ Senda del Rey, s/n. 28071 Madrid.

** Arqueólogo Territorial de Segovia de la Junta de Castilla y León. Delegación Provincial de Cultura de Segovia. 


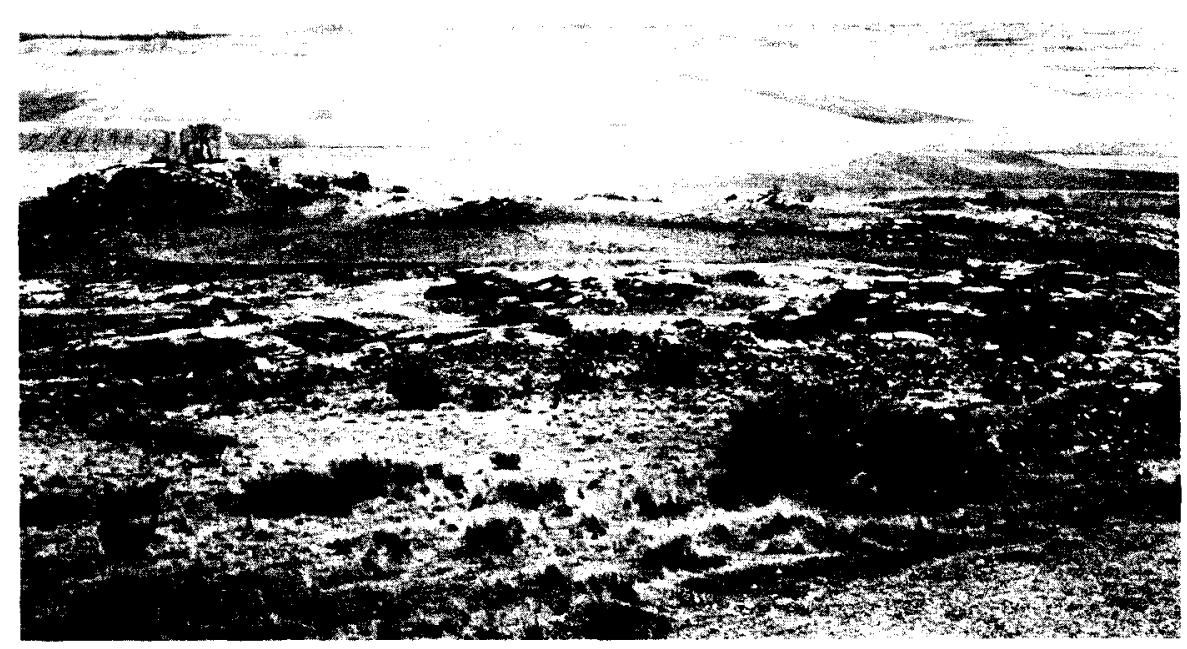

Fig. 1. Vista de conjunto del cerro de San Isidro en Domingo Garcia (Segovia)

No puede descartarse, no obstante, la posibilidad de que se trate de la manipulación de una figura anterior, que bien podria ser de época paleolitica, teniendo en cuenta la morfometría de la figura y su notable similitud con el resto de los caballos grabados paleolíticos del conjunto. En todo caso, durante los trabajos de reconocimiento de esta figura se descubrió la existencia, en su entorno inmediato, de otros motivos grabados cuya adscripción cultural, cronológica y estilística no ofrecia ninguna duda y cuya presencia ha obligado a la revisión completa del conjunto de arte rupestre de Domingo Garcia, de la que ahora ofrecemos un avance, pese a estarse realizando aún trabajos de documentación, dada la importancia y el interés de los grabados hasta el momento registrados.

En breve plazo se dará a conocer un estudio completo de las manifestaciones hasta el momento registradas, mientras continúa la revisión total de la zona de grabados, de cara a arbitrar nuevas medidas de protección de los conjuntos, entre las que se dará prioridad a la inmediata declaración del sector Cerro de San Isidro-Cuesta Grande-Las Peñas del Valle como Zona Arqueológica con categoría de Bien de Interés Cultural. 


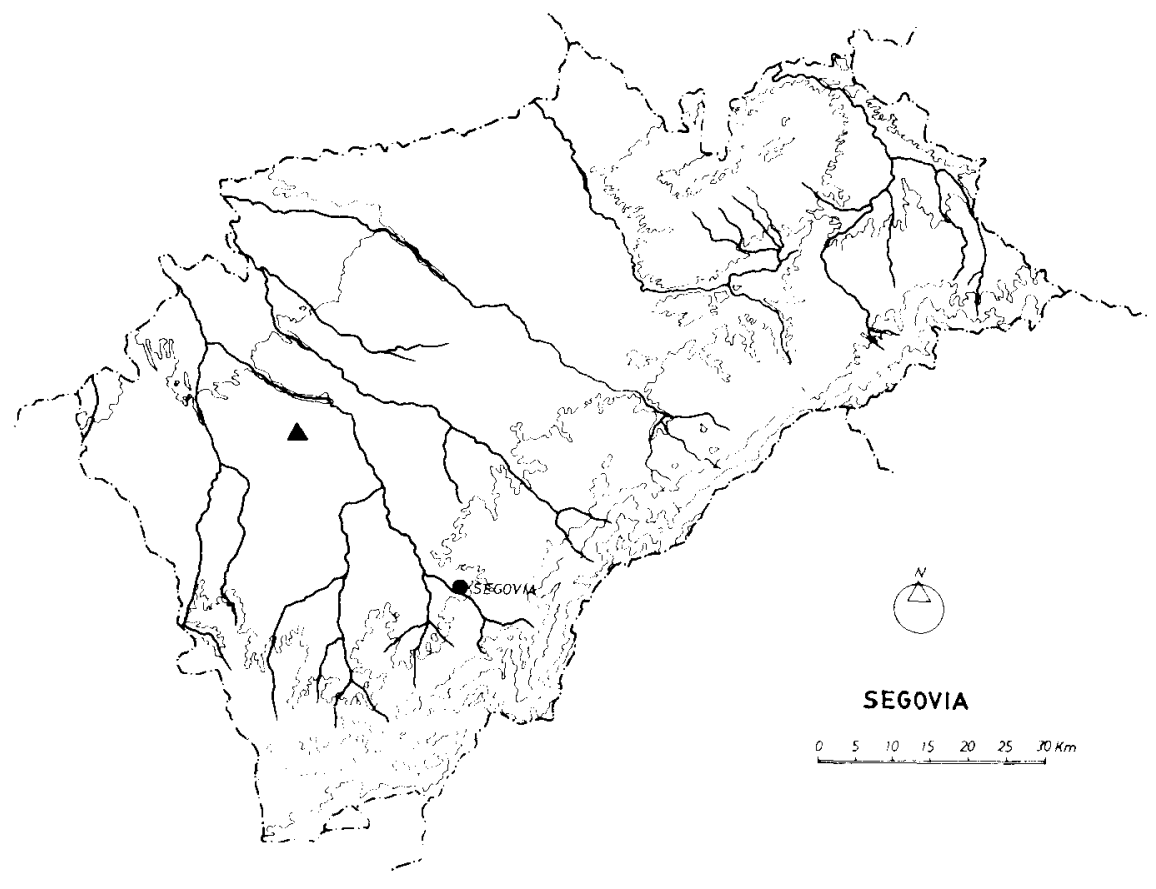

Fig. 2. Plano de situación general de Domingo Garcia

\section{SITUACIÓN GEOGRÁFICA}

El término municipal de Domingo Garcia, incluido en la comarca de Santa Maria de Nieva (fig. 2), pertenece, como ésta, a la denominada Unidad Natural de las Campiñas Onduladas, caracterizada por un relieve de ondulaciones suaves con una altitud media de 900 metros, alcanzándose cotas de 980 metros en algunos puntos. Sus tierras se componen de arcillas rojas sedimentarias miocénicas sobre las que, en ocasiones, aparecen depósitos cuaternarios de origen eólico. Petrológicamente, la zona presenta composición silicea - granitos y rocas metamórficas-, apareciendo afloramientos del zócalo paleozoico en el valle del Eresma y en las inmediaciones de Domingo García. Estas formaciones, que buzan en dirección NW, presentan grandes superficies verticales y lisas que constituyen el soporte de las abundantes manifestaciones artisticas de la zona (fig. 3). 


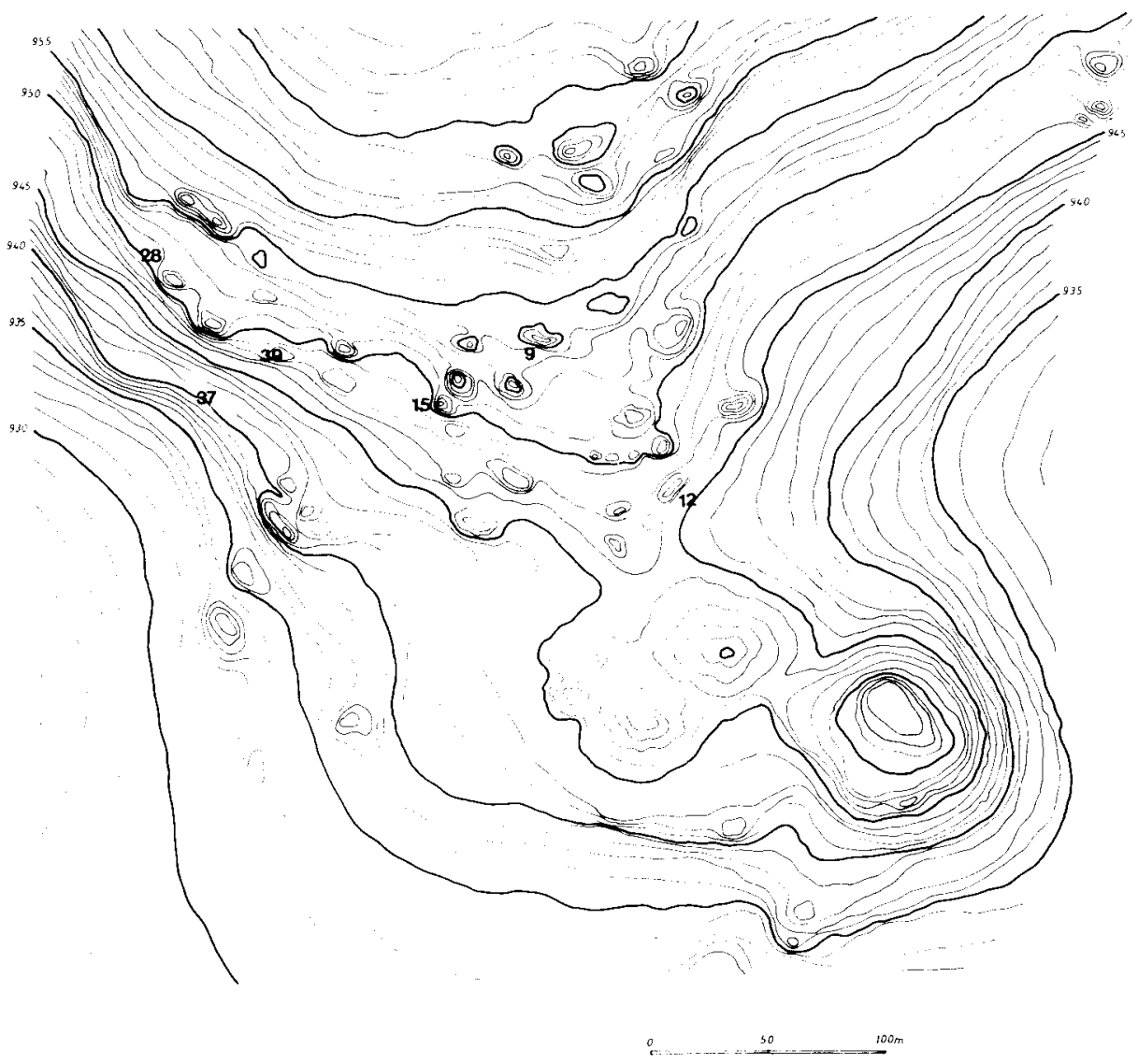

Fig. 3. Situación de las diferentes rocas descritas en el articulo

El medio en el que se localizan los grabados se encuentra muy degradado. En él subsisten algunas encinas aisladas junto con jaras en un paisaje pedregoso e improductivo, abandonado para el cultivo hace años, $y$ en el que las únicas actividades económicas actuales se reducen al pastoreo y a la explotación de canteras de pizarras y esquistos.

\section{NOTAS HISTORIOGRÁFICAS}

Se conoce la existencia de arte parietal en esta región desde principios de siglo, a partir de los trabajo de F. Tuñón Mallada, quien en 1929 
publica unas breves impresiones sobre los grabados de la zona de Santa María de Nieva (TUÑón, F. 1929). No tiene este estudio ninguna repercusión científica, sin embargo, y habrá que esperar hasta 1970 para que $F$. Gozalo Quintanilla dé a conocer el conjunto de Domingo García por medio de una publicación en la revista Ejército (Gozalo, F. 1970). A partir de este momento se produce una notable intensificación de los trabajos sobre el yacimiento, llevados a cabo en primer lugar por M. ${ }^{a}$ R. Lucas Pellicer (1971; id., 1973; id., 1974) y continuados posteriormente por la publicación del gran caballo de estilo paleolitico debida a E. Martín Santamaria y A. Moure (1981).

El mismo Moure firmará con posterioridad nuevos trabajos, en colaboración con E. Ripoll y R. de Balbín (Balbin, R.; Moure, A.; RIPOLL, E. 1982; Balbin, R.; Moure, A. 1982), en los que se pretende sintetizar las caracteristicas y fases del conjunto.

La última aportación al estudio del arte de Domingo Garcia se debe a un trabajo de sintesis sobre el arte rupestre de Castilla y León coordinado por M. ${ }^{a}$ S. Corchón Rodríguez (CoRCHón et alii 1991).

La bibliografía que acabamos de reseñar sitúa el inicio de las manifestaciones artísticas de Domingo Garcia en un momento avanzado del Paleolitico Superior, cuyo único testimonio sería el gran caballo piqueteado, encuadrable en el estilo IV de Leroi-Gourhan (MARTín, E. y Moure, A. 1981).

Balbin y Moure sitúan a continuación una Fase esquemática, representada por figuras humanas aisladas y algunos motivos de posible carácter simbólico, atribuible a un momento impreciso dentro de la edad del Bronce (LuCAS, M. ${ }^{a}$ R. 1973: 262) o, incluso, a fases anteriores (BALBiN, R. y Moure, A. 1988: 21).

Sucederia a la anterior una Fase escenográfica, en la que las figuras se agrupan en composiciones escénicas, acaso de tipo narrativo. Los personajes incorporan una notable variedad de objetos, apareciendo también tocados y vestidos. Las escenas hacen referencia a temas cinegéticos o pastoriles y bélicos.

La comparación con las representaciones de otras zonas europeas - Valcamonica, fundamentalmente - ha hecho sugerir una cronologia para esta fase dentro de los límites de la Edad del Hierro (BALBin, R. y MOURE, A. 1988).

La última fase definida se fecha en época medieval, a partir de la existencia de determinadas manifestaciones iconográficas -cruces, etc.(LuCAS, M. ${ }^{a}$ R., 1973: 262-263) junto a figuras cuyas caracteristicas no difieren demasiado de las de los grupos anteriores, desde los puntos de vista formal y técnico. 


\section{DESCRIPCIÓN DE LAS FIGURAS}

En la primera de las rocas, orientada al Sureste ( ${ }^{\circ}{ }^{\circ}$ 12), que nos encontramos al llegar al conjunto del Cerro de San Isidro y donde se localiza el ya conocido caballo piqueteado, hemos diferenciado dos paneles: el inferior y el superior.

\section{ROCA 12 (INFERIOR)}

En el primero de ellos hemos identificado una serie de figuras que describiremos en el sentido de las agujas del reloj, como haremos a partir de ahora con el resto de las rocas *

A la izquierda, bajo una ligera capa de liquenes que hemos podido limpiar, hemos encontrado una cabeza de ciervo $(20,5 \mathrm{~cm}$ de largo $x$ $20,2 \mathrm{~cm}$ de ancho) (fig. 4.1), que mira a la izquierda con una magnífica cornamenta compuesta por cuatro candiles. El trazo es muy fino $(1 \mathrm{~mm})$, poco profundo $(1 \mathrm{~mm})$ y bastante continuo excepto en la zona de la cara, donde aparece bastante perdido y se desdobla en dos lineas paralelas.

Más a la derecha, hallamos otra representación de un ciervo completo $(34,1 \mathrm{~cm}$ de largo $\times 27,8 \mathrm{~cm}$ de ancho) (fig. 4.2), mirando a la izquierda y ligeramente inclinado hacia arriba. El trazo es fino y poco profundo y se aprecia todo el contorno excepto algunas pequeñas zonas. La cabeza posee una cornamenta con la luchadera y tres candiles y la pequeña oreja adosada al asta. Las exfoliaciones de la roca no impiden la visión de conjunto.

Inmediatamente debajo del morro del caballo piqueteado, se localiza un bóvido completo $(20,3 \mathrm{~cm}$ de largo $\times 11.5 \mathrm{~cm}$ de ancho) (fig. 4.3), que mira a la izquierda, destacando con claridad la parte delantera de la figura. Tanto el cuerno - en perfil simple - como la cabeza y la línea del pecho hasta la pata delantera poseen un trazo ligeramente más ancho y profundo que el resto de la representación, pero aún asi se trata de un grabado de tipo filiforme.

\footnotetext{
* En los calcos hemos representado las figuras paleoliticas con trazo continuo y en principio con el mismo grosor de trazo, ya que al tratarse de superficies muy grandes, que hemos tenido que reducir. las lineas más finas se hubiesen perdido. De la misma forma. en el calco del panel principal de la zona de las canteras, hemos obviado intencionalmente una gran cantidad de trazos paralelos, para no sobrecargar la reproducción y hacer más fácil la lectura de las representaciones naturalistas. Con trazo discontinuo están dibujadas las figuras piqueteadas - su contorno aproximado- y con la convención del trazo y punto, aparecen los graffitis modernos. Por último, hemos representado con trama. las exfoliaciones o desconchones más evidentes de la superficie analizada, sin entrar, por los mismos motivos antes aducidos, en detalles excesivos.
} 


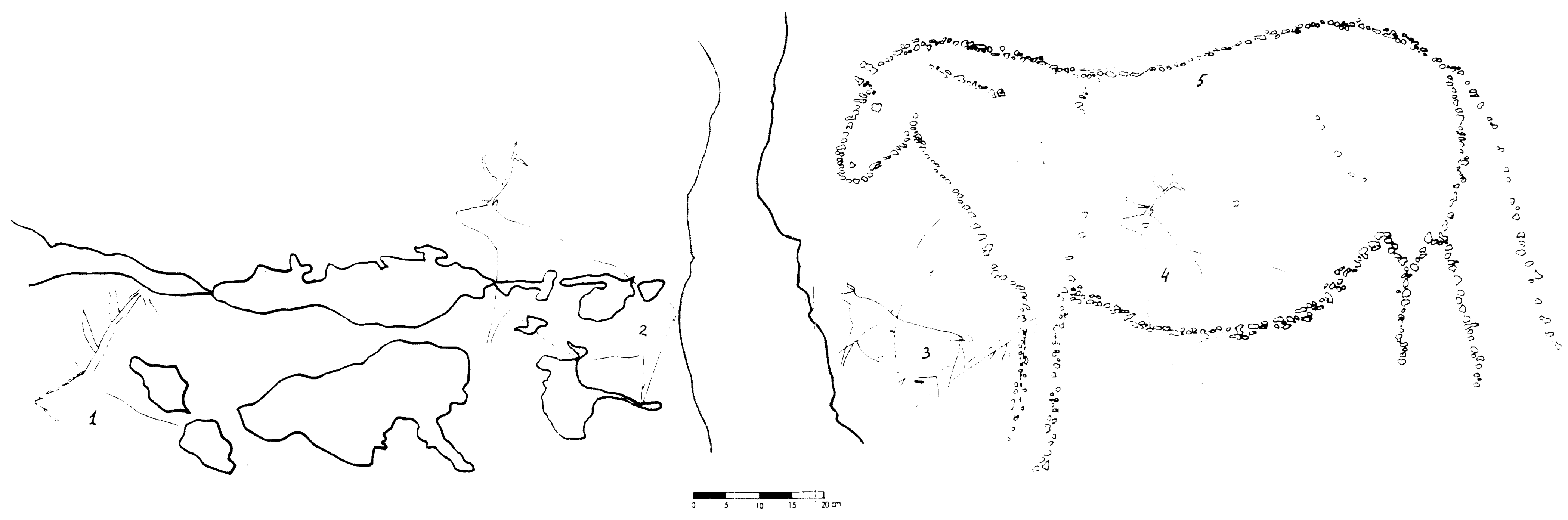




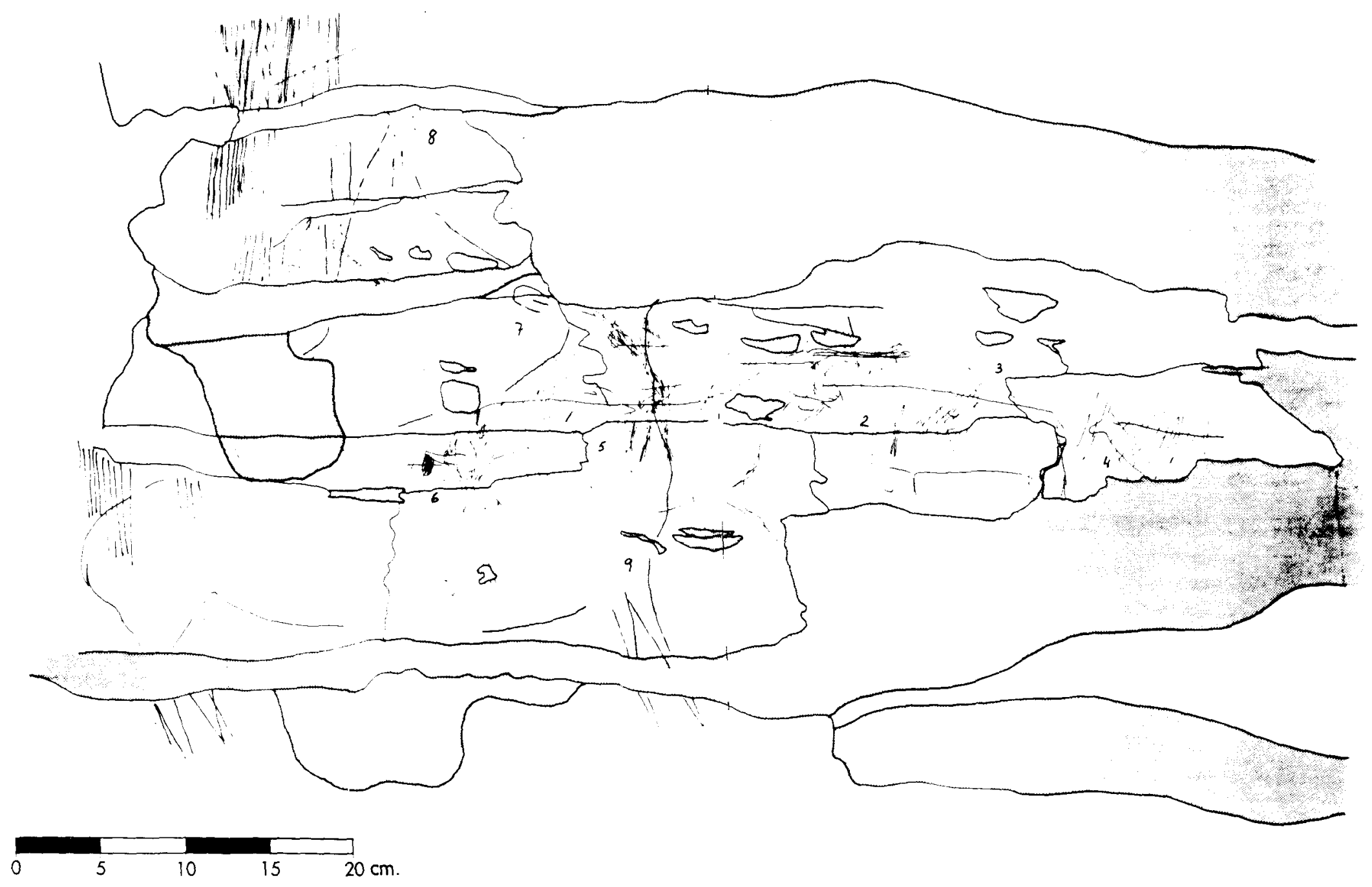

Fig. 20. Calco del panel principal de la zona de las canteras 
En el interior de la línea del vientre del caballo piqueteado se observa otro ciervo casi completo que mira a la izquierda y cuyas dimensiones alcanzan $28,5 \mathrm{~cm}$ de longitud y $23,8 \mathrm{~cm}$ de anchura (fig. 4.4). Las parte del viente del ciervo, está perdida por la superposición de una figura cruciforme piqueteada posterior. Al igual que ocurria con el ciervo de la zona central del panel, éste también posee una cornamenta con su luchadera, tres candiles y la oreja, ligeramente circular y pegada a la cornamenta.

En relación a la ya conocida figura piqueteada de caballo (fig. 4.5), queremos señalar que un análisis detallado de la misma nos ha permitido comprobar la existencia en algunas zonas — por debajo del piqueteadode un conjunto de lineas entre los puntos del piqueteado, que siguen la silueta del équido. Concretamente estos trazos se observan claramente en la pata delantera, la babilla, final de la crinera e inicio de la cruz. Ello nos hace pensar que inicialmente esta representación debió de estar simplemente grabada en trazo filiforme, como el resto de las figuras paleoliticas del conjunto, y en un momento posterior - posiblemente anterior a la ejecución de los otros grabados de tiempos históricos, dado la diferencia de pátina- se realizaria el piqueteado.

En la superficie de todo este panel hemos localizado además gran cantidad de trazos - un cuerno, una oreja, etc.- que por el momento no configuran ninguna representación. Del mismo modo, más a la derecha y debajo de la capa de liquenes, se aprecian otras lineas que sin duda cuando se limpien ampliarán el repertorio.

ROCA 12 (SUPERIOR)

A la derecha del panel superior y bajos unos liquenes, hemos hallado una pequeña figura de ciervo (9 cm de largo $\times 7,8 \mathrm{~cm}$ de ancho) (fig. 5), en trazo fino mirando hacia la izquierda. Este posee unas características estilísticas que lo diferencian del resto. Se trata de una representación mucho más esquemática en comparación con el naturalismo presente en los del panel inferior. La cabeza, esbozada en tres lineas, posee sin embargo una gran cornamenta -en perspectiva torcida-con cinco candiles en una de las astas, mientras que en la otra de momento, tan solo se aprecian dos. Las patas están realizadas a base de simples líneas, y en la parte de la grupa aparecen tres trazos perpendiculares ia modo de venablos?

En el otro extremo del panel, prácticamente por encima de la cabeza del caballo piqueteado, se localiza una imagen completa de bóvido $(22,5 \mathrm{~cm}$ de largo $\times 11,3 \mathrm{~cm}$ de ancho) (fig. 5) que mira a la izquierda. El trazo, que se aprecia perfectamente en todo su contorno, es simple, muy fino y poco profundo. En esta figura, vemos la cabeza ligeramente levantada como en actitud de mugir, con un pequeño cuerno en perspectiva 

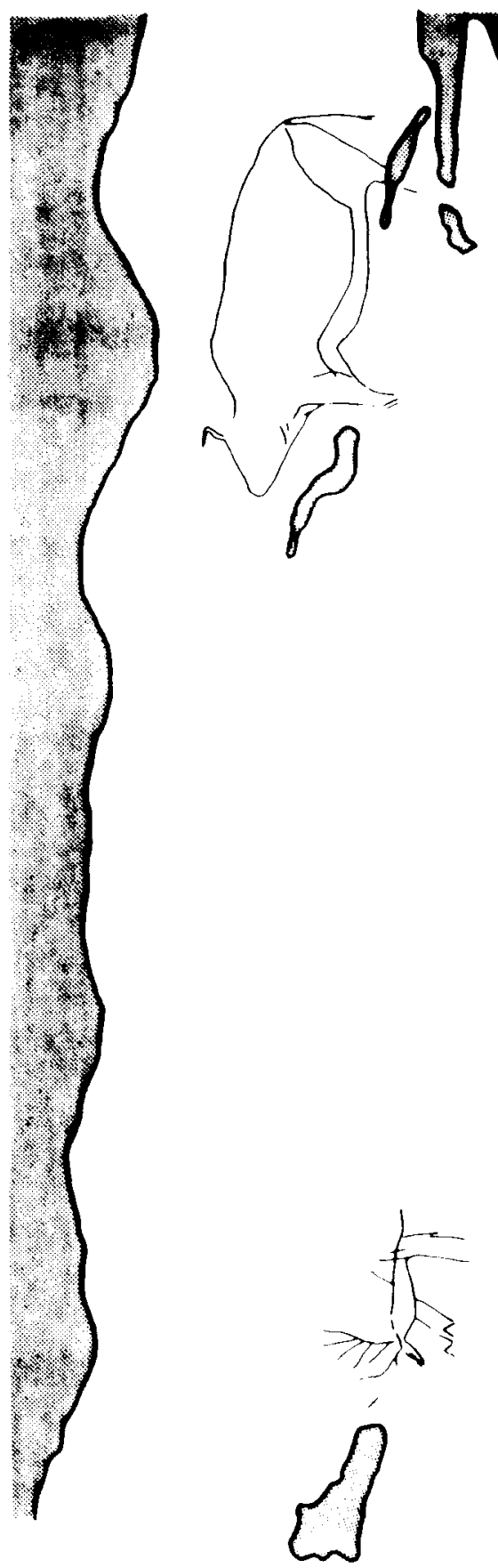

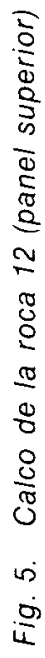


simple. En el interior, desde el inicio del vientre hasta la grupa, hay una línea que sin duda representa un despiece para reflejar un cambio de coloración o de pelaje. La pata trasera está muy perdida por un desconchamiento de la roca y la delantera se encuentra simplemente insinuada hasta la rodilla.

Al igual que en el panel inferior, la limpieza de liquenes nos permitirá probablemente poner al descubierto otras representaciones, ya que son bastantes los trazos grabados que se observan en las actuales condiciones.

ROCA 9b

Si continuamos por el camino, llegamos hasta una de las mayores rocas (9b) del conjunto, donde se han descifrado gran cantidad de repre-

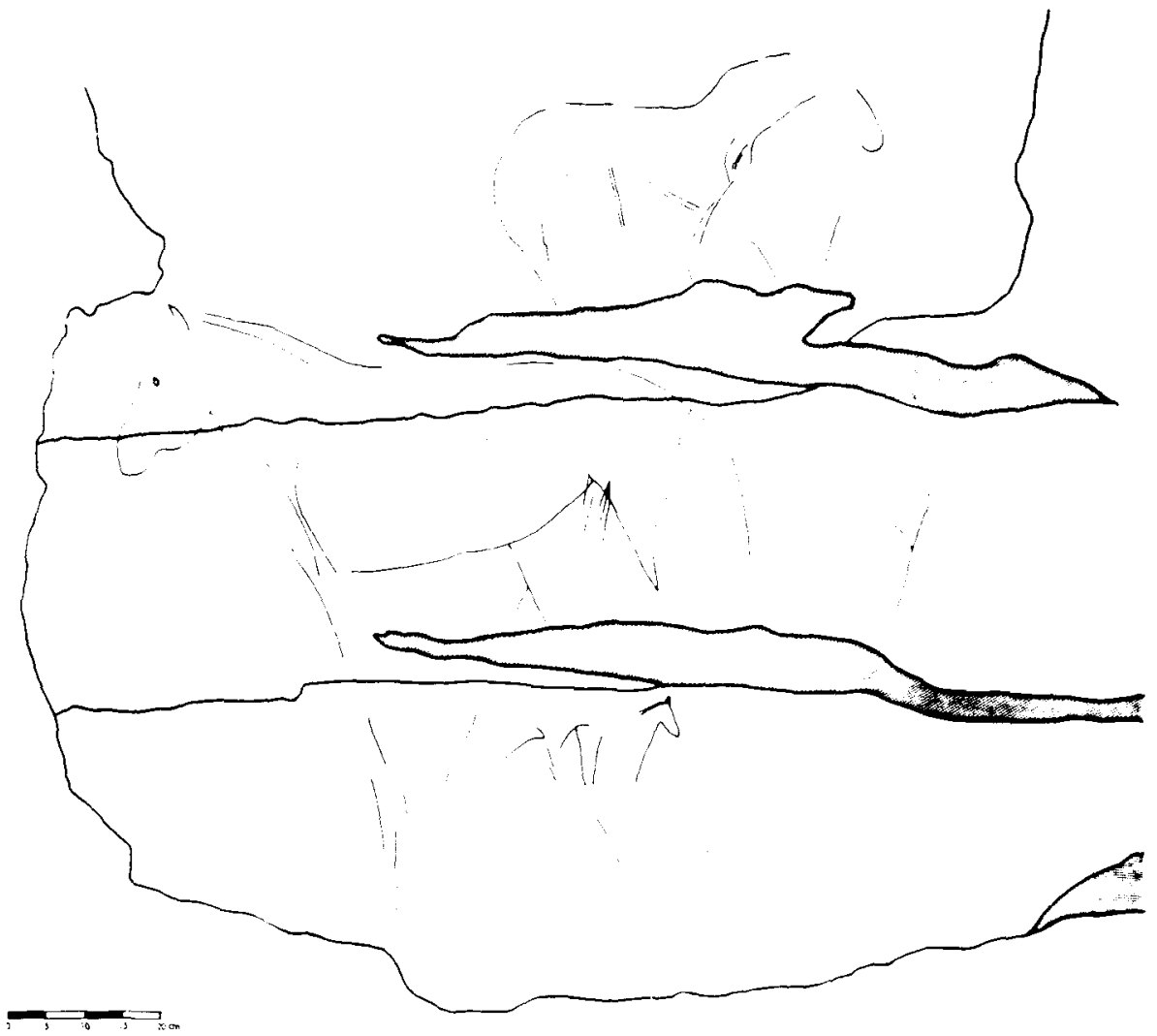

Fig. 6. Calco de la roca 9b 
sentaciones postpaleoliticas piqueteadas. A pesar de la magnitud de este peñasco, las figuraciones paleolíticas son muy escasas -por el momento- y se localizan en la zona 9b. Este panel, bastante alto en relación al suelo actual, es una superficie lisa -friada - en la que hemos distinguido, en primer lugar un gran caballo que mira hacia la izquierda cuyas dimensiones alcanzan los $67,8 \mathrm{~cm}$ de longitud y $46,7 \mathrm{~cm}$ de anchura (fig. 6). Se trata de una magnífica figura dada sus grandes proporciones, en la que se aprecia bien el belfo, las fauces o quijada, asi como el ojo y una de las orejas; también se distingue la crinera realizada a base de dos trazos más o menos paralelos. Junto a la pata trasera, solucionada en forma subtriangular, se observan en la zona del vientre o babilla unas lineas perpendiculares. La cola, que se inicia en la grupa, es casi tan larga como la pata. El estilo de esta figura es muy similar al caballo piqueteado de la roca 12.

Por encima de este caballo, se localizan una serie de trazos que conforman la silueta de un équido $(41,8 \mathrm{~cm}$ de largo por $23,3 \mathrm{~cm}$ de ancho) (fig. 6) casi completo que mira hacia la derecha. La única parte de la cabeza que se aprecia de momento es el morro; falta también la línea del pecho y la pata delantera. El trazo es muy fino y poco profundo.

En la parte baja del panel, a la altura de la pata trasera del gran caballo, hemos localizado otra pequeña figura de équido $(13 \mathrm{~cm}$ de longitud por $8,7 \mathrm{~cm}$ de anchura) (fig.6), orientada hacia la derecha. Se observa bastante bien la cabeza y las orejas asi como la línea del pecho; la grupa, cola y patas traseras están ejecutadas a partir de dos simples trazos.

\section{ROCA 15 (OESTE)}

En el mismo sendero y a continuación, a mano izquierda, está situada la roca 15 . Se trata de una piedra con estructura en forma de columna en la que hemos diferenciado dos zonas: a) el panel oblicuo, orientado al Oeste y b) el panel Sur.

En el primero de ellos, se encuentra representada una figura de cáprido (12,9 cm de longitud por $10,2 \mathrm{~cm}$ de anchura) (fig. 7), orientada hacia la derecha. Llama la atención en él la profundidad del trazo y su nitidez con respecto a la superficie donde se localiza, lo que contrasta con el resto del conjunto visto hasta ahora. Esta cabra presenta unas proporciones un tanto distorsionadas, ya que mientras la cabeza y los cuernos con respecto a la longitud del cuerpo son correctas en relación al grosor del cuerpo, hay un claro desequilibrio. Las patas, como ocurre en general en el conjunto, están poco cuidadas y se resuelven con unos trazos paralelos acuñados en la extremidad. En el interior del cuerpo se distinguen algunos trazos que no forman ninguna figura. 


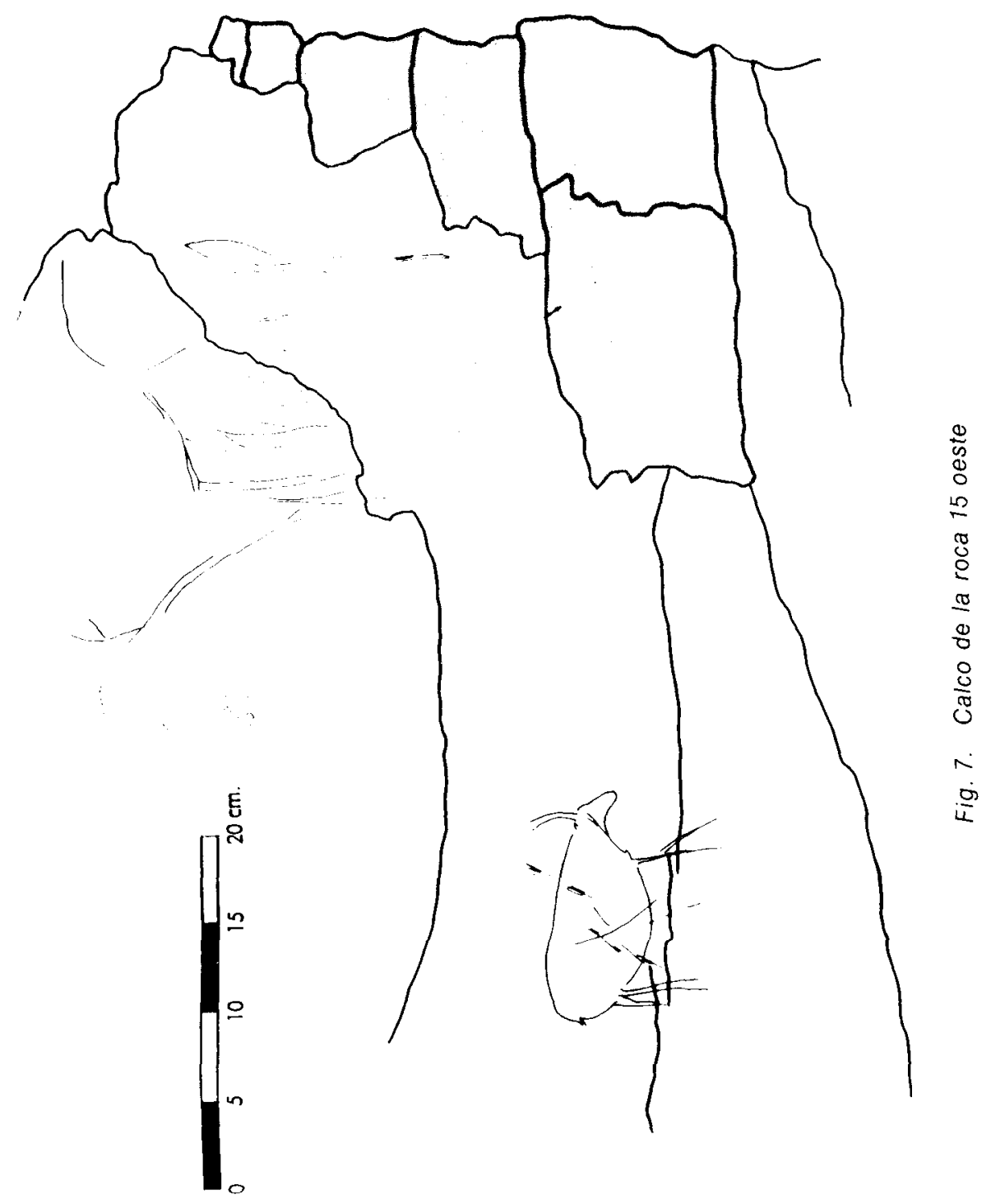


A la derecha y en una posición ligeramente más alta con respecto a la última representación, se aprecia un conjunto de líneas -bajo graffitis modernos- cuyo análisis detallado no nos ha permitido, de momento, identificar ninguna representación, aunque se intuye un cuarto trasero de cuadrúpedo.

ROCA 15 (SUR)

En el otro lado de la columna rocosa, es decir al Sur, hemos diferenciado dos paneles: el primero de ellos, a la izquierda y más próximo al panel oblicuo y el de la derecha con un mayor número de representaciones.

En el que se sitúa a la izquierda, bastante roto por exfoliaciones naturales de la roca, hemos identificado un conjunto de trazos que conforman una figura bastante incompleta de caballo $(6 \mathrm{~cm}$ de longitud por 7 $\mathrm{cm}$ de anchura) (fig. 8), que mira hacia la izquierda.

Un poco más a la derecha, y bajo un grabado piqueteado de tiempos históricos, se identifica la línea cervico-dorsal de una cierva - por el tipo de oreja-que mira a la derecha y con unas dimensiones de $11 \mathrm{~cm}$ de longitud por $4,6 \mathrm{~cm}$ de anchura (fig. 8 ). Ambos grabados son de trazo muy fino y poco profundo.

En el panel de la derecha, en esta zona orientada meridionalmente, se distingue un mayor número de representaciones y aunque todas ellas aparecen incompletas, en cierta medida debido a los desconchones naturales, los caracteres morfológicos de los trazos representados nos permiten una identificación zoo técnica de los mismos.

En primer lugar, destaca un bóvido bastante completo $(22.5 \mathrm{~cm}$ de longitud por $16,4 \mathrm{~cm}$ de anchura) (fig. 9), mirando a la izquierda. Se diferencia bien la línea cervico-dorsal, la cabeza y la línea del pecho. En la cabeza se pueden ver perfectamente los dos cuernos sinuosos hacia adelante, la testuz, el morro - ligeramenie cuadrangular-y el ollar. Esta figura puede presentar alguna complicación al ser interpretada, ya que encima de la cabeza y cuello se distinguen otra serie de trazos que conforman un cuadrúpedo - posiblemente un cáprido- orientado hacia la izquierda y con unas dimensiones de $8,2 \mathrm{~cm}$ de longitud por $8,1 \mathrm{~cm}$ de anchura; no se aprecia la parte anterior y podria pensarse también que se trata de una cierva.

Más a la derecha, muy perdido por las exfoliaciones del esquisto, se observa un cáprido (23,4 cm de longitud por $11,3 \mathrm{~cm}$ de anchura) (fig. 9), orientado hacia la derecha y ligeramente inclinado hacia arriba. De esta representación, un poco distorsionada en cuanto a su longitud, se distinguen bien los cuartos traseros y el cuerno con la oreja. 
Las representaciones de estilo paleolitico en el conjunto de ...

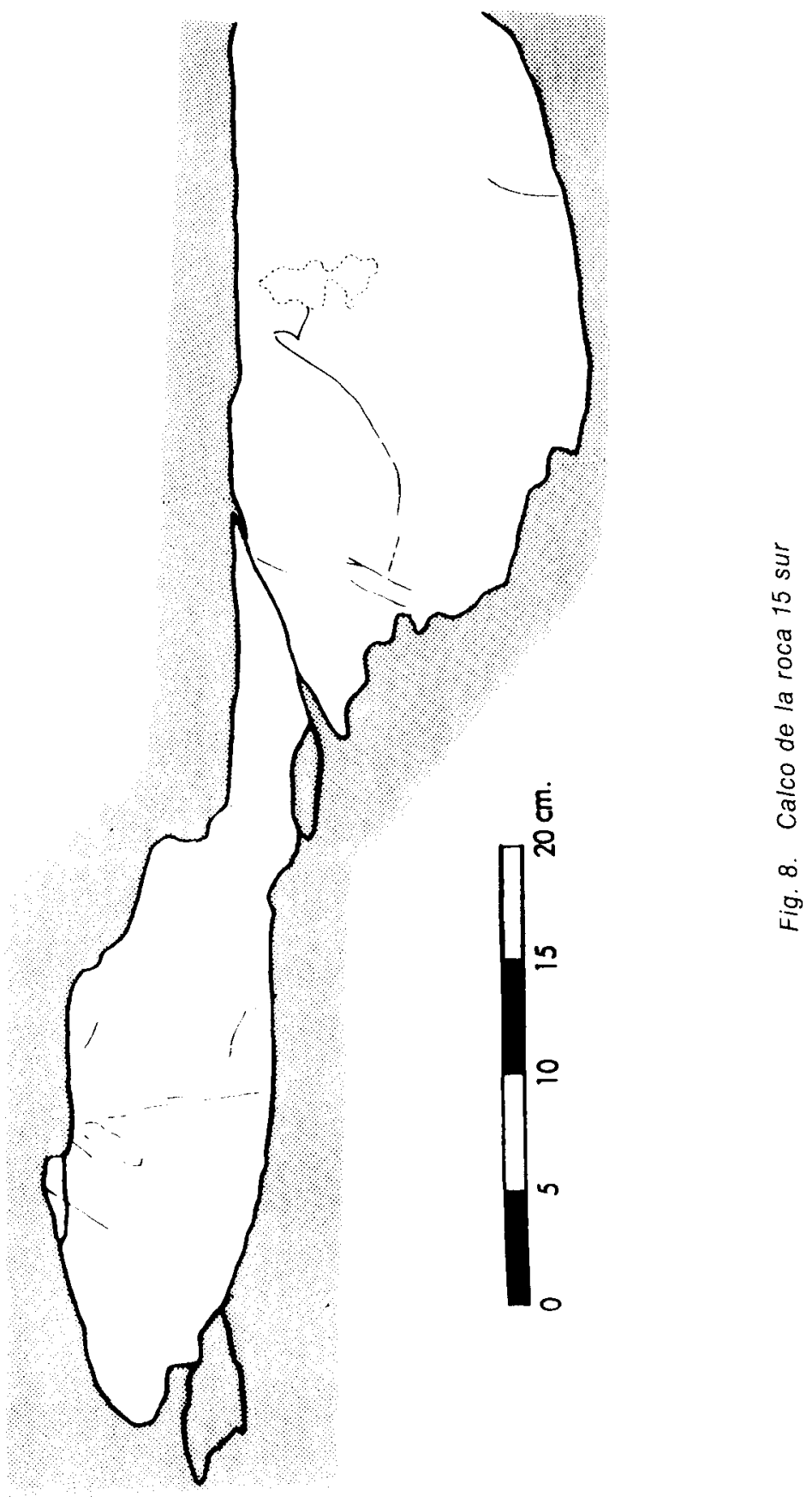




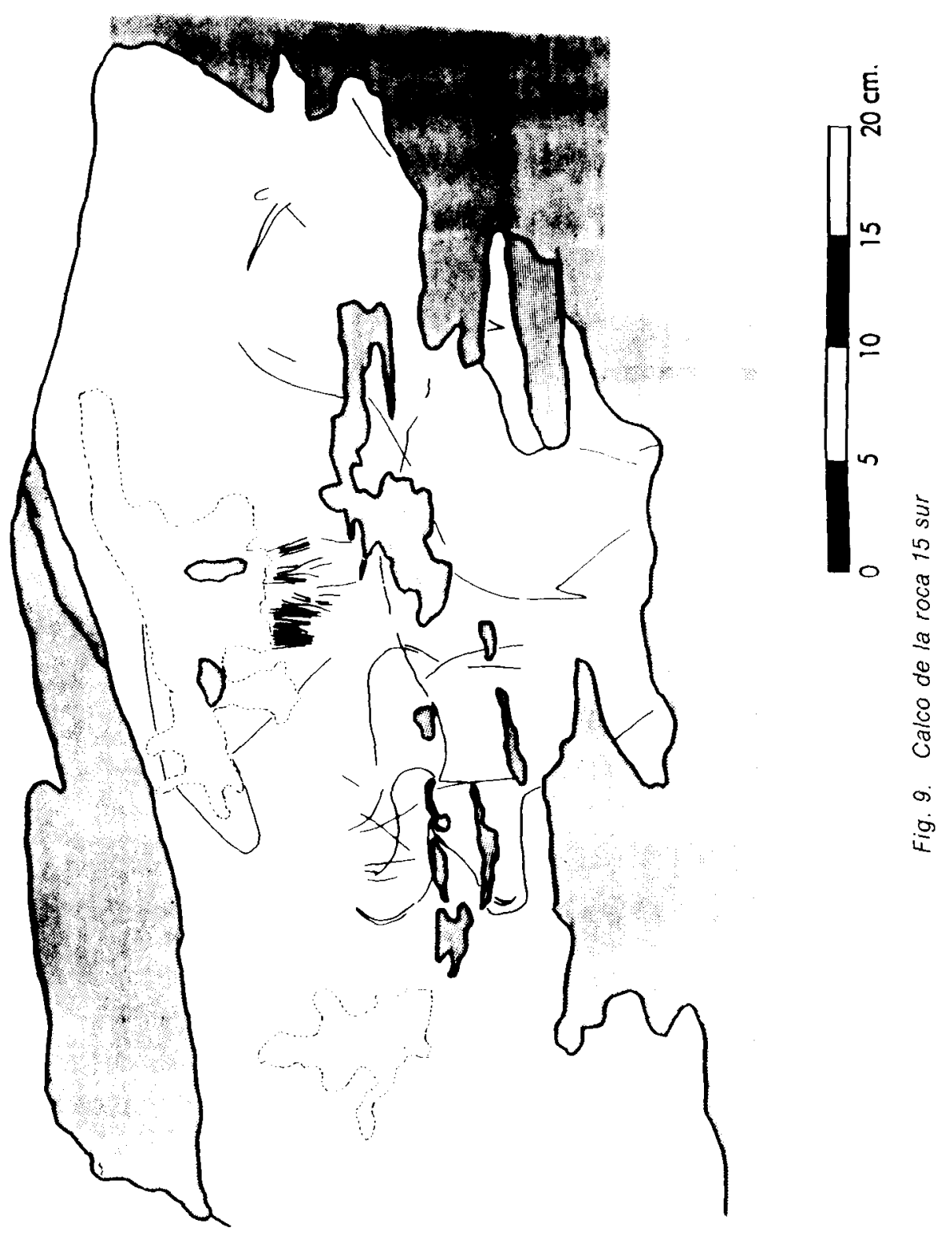


Pero la figura que presenta una mayor dificultad identificativa es, sin duda, la situada en la parte superior, bajo un grabado piqueteado más moderno que representa un cánido. En esta figuración, muy perdida, se aprecia la cabeza - sin orejas - y una parte de las líneas del dorso y el pecho. En la parte que corresponderia al viente, hemos identificado un conjunto de trazos paralelos (37) de escasa longitud, que podrian querer representar el pelaje. Creemos que puede tratarse de un cuadrúpedo - équido- mirando a la izquierda con unas proporciones de $11,6 \mathrm{~cm}$ de longitud por 7,8 cm de anchura (fig. 9).

Hay además otras lineas que por el momento todavia no hemos podido descifrar.

ROCA NÚM. 28

En una de las zonas más altas del conjunto del Cerro de San Isidro se sitúa la roca número 28 , que para nosotros tiene un especial significado ya que fue en ésta donde hallamos por primera vez grabados del tipo que estamos describiendo en el presente artículo. Es aqui donde se encuentra la figura de équido piqueteada - ifalsa?- por cuyo motivo nos desplazamos a Domingo García.

En el centro de la roca y sobre una superficie relativamente amplia, pero con bastantes desconchones naturales, se sitúa una gran figura de caballo (37,3 cm de longitud por $24,7 \mathrm{~cm}$ de anchura) (fig. 10) que mira a la izquierda. Las exfoliaciones naturales de la superficie friada, no restan uniformidad al conjunto de la representación. Se observa claramente la cabeza - falta el ojo- con un morro ligeramente cuadrangular y la quijada o babilla realizados mediante varios trazos paralelos que se unen a la línea del pecho. En la parte superior se distinguen claramente una oreja y otro trazo que podria representar la otra. La crinera es alta y sobresale bastante por encima de las orejas. Bajo las mismas, se inicia una línea perpendicular que parece indicar el inicio del despiece de la crinera. La linea cervico-dorsal está perdida y únicamente se distingue la grupa. En la parte delantera, el pecho está realizado mediante un trazo simple, que en algunas zonas se desdobla hasta la zona denominada encuentro - pliegue antes del inicio de la pata delantera - desde donde parte la pata anterior de la que solamente se aprecia una linea.

En toda esta roca hemos identificado otros trazos, uno de los cuales podria relacionarse con la linea ventral. En una reciente visita de estudio al conjunto para revisar los calcos, hemos podido comprobar que una de las figuras situadas inmediatamente debajo de este gran caballo, y que habiamos identificado como un pequeño équido, es en realidad otro caballo de grandes proporciones, que todavia está en estudio. En este panel 


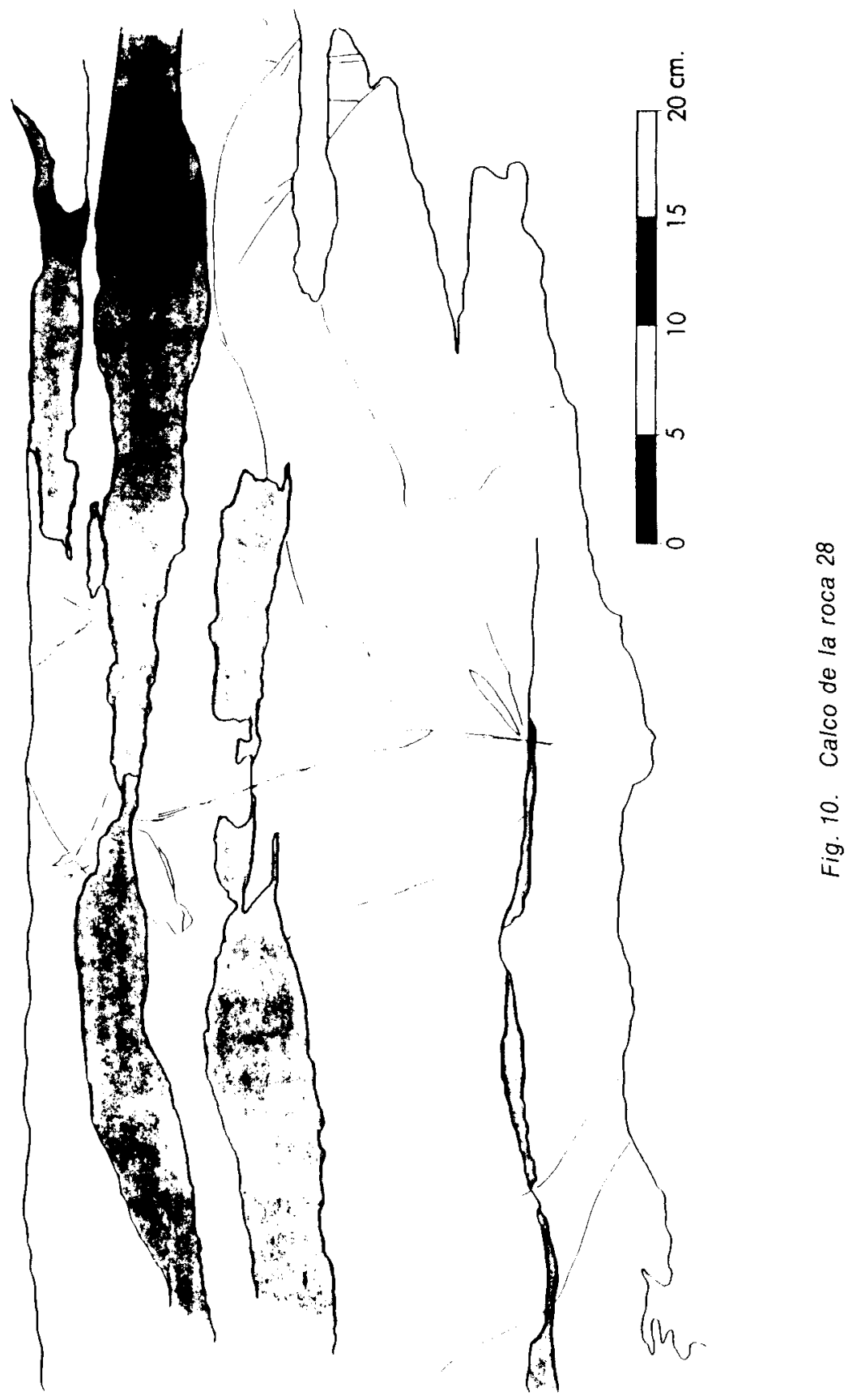


dificilmente visible por su altura, sin la ayuda de una escalera, se aprecia un rebaje del nivel del suelo.

Más a la izquierda, en una posición ligeramente inferior, hemos distinguido en un grabado simple, sumamente fino y somero, una figura de cierva incompleta $(16,4 \mathrm{~cm}$ de longitud por $11,6 \mathrm{~cm}$ de anchura) (fig. 11), que mira a la derecha y aparece ligeramente inclinada hacia arriba. Se aprecia a duras penas la oreja, viéndose mejor la línea del dorso, grupa, cola y cuartos traseros. La pata delantera, como en casi todo el conjunto está realizada mediante dos trazos paralelos. En la parte inferior existen otros trazos que no forman aparentemente ninguna representación.

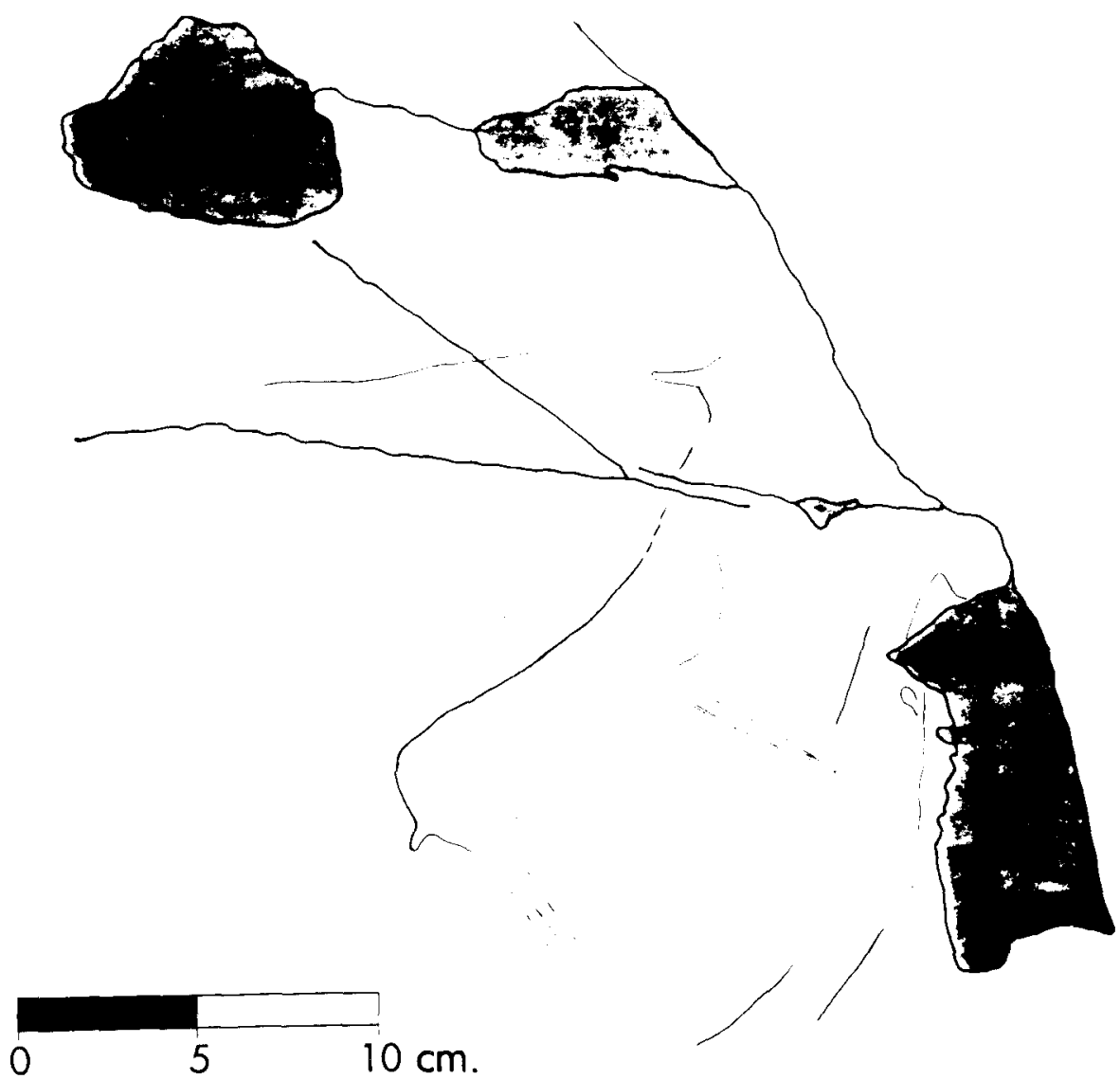

Fig. 11. Calco de la roca 28 


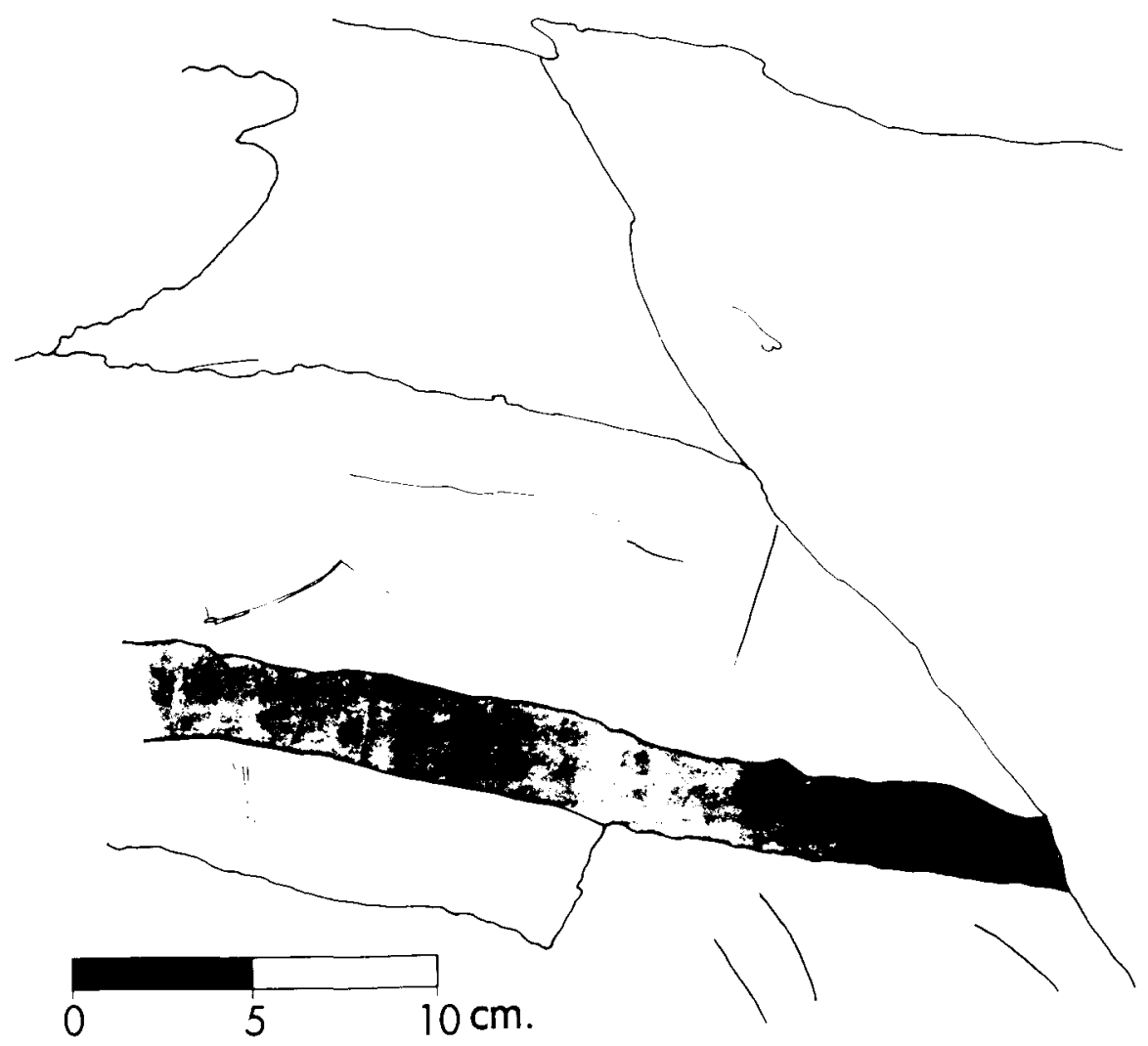

Fig. 12. Calco de la roca 28

A unos $30 \mathrm{~cm}$ de la cierva, hemos hallado otras lineas que hemos identificado con un protomos de caballo $(13 \mathrm{~cm}$ de longitud por $3,5 \mathrm{~cm}$ de anchura) (fig. 12), muy incompleto, mirando a la izquierda, realizado mediante un grabado simple, muy fino y poco profundo.

En la parte superior del panel, existen otros trazos, en los que hemos creído ver otro protomos de caballo $(3 \mathrm{~cm}$ de longitud por $1,8 \mathrm{~cm}$ de anchura) mirando a la izquierda, pero cuya identificación es poco precisa dada la exfoliación existente de la roca base.

En esta roca 28 hemos localizado más superficie friada -antigua- en la que existen numerosos trazos que están siendo investigados, ya que de momento no se distingue ninguna figura evidente. 
ROCA 37e

En el afloramiento más bajo, de los tres que se aprecian, se encuentra otro gran macizo en el que sólo hemos localizado dos paneles con escasas - pero interesantísimas figuras-. Se trata de la roca $37 e$, orientada hacia el Sur, con bastante superficie friada. En el mayor de ellos, a

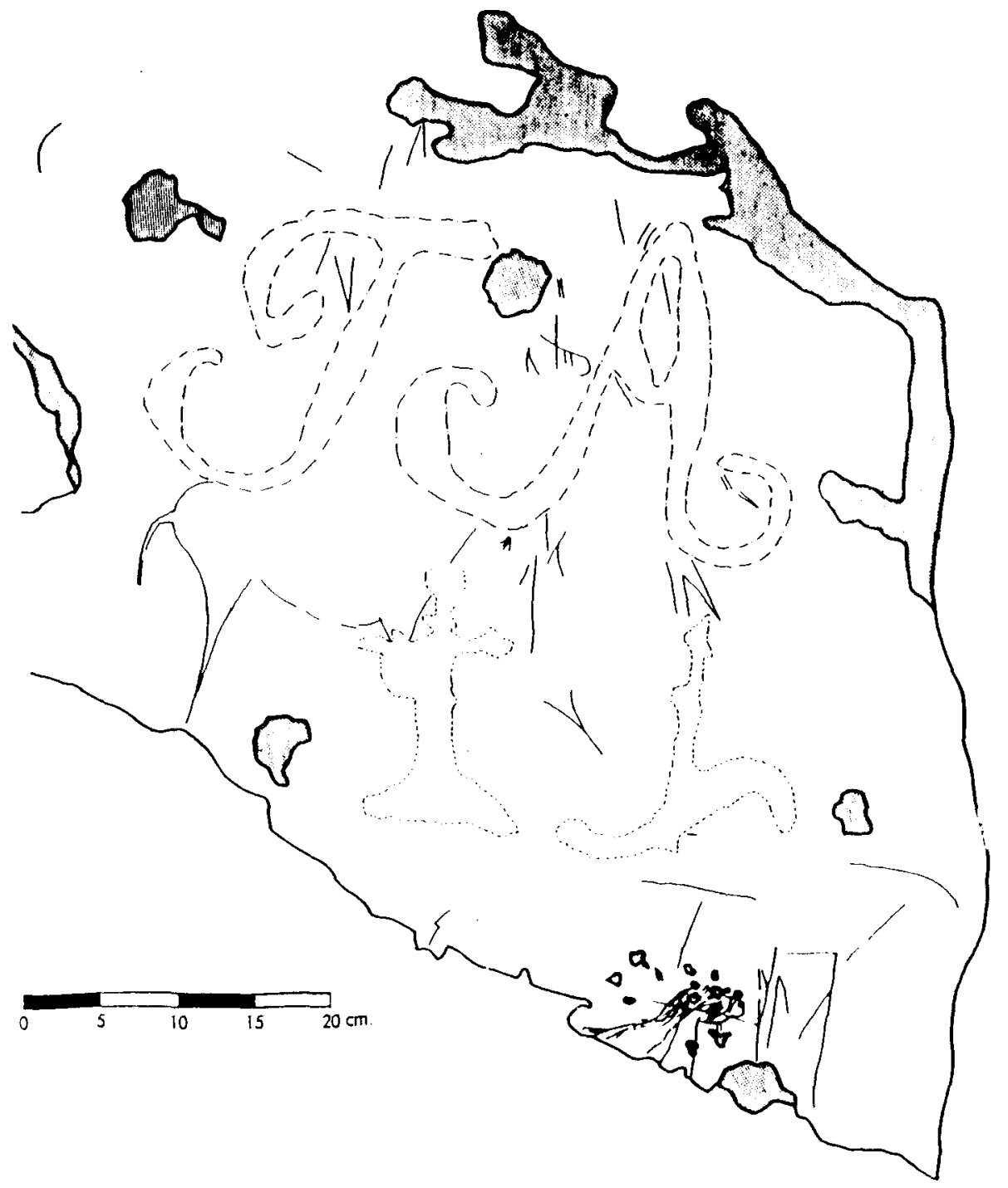

Fig. 13. Calco de la roca $37 e$ 


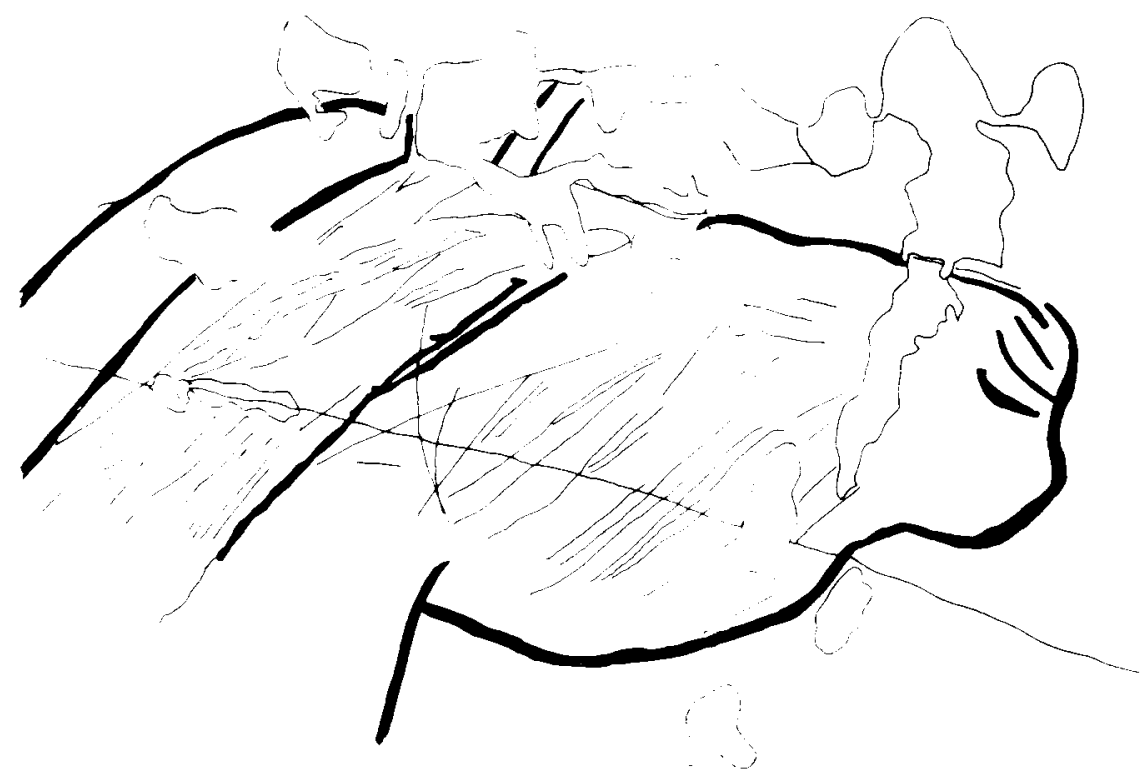

Fig. 14. Detalle del protomos de caballo de la roca $37 e$

primera vista, choca el graffiti moderno "J. A." que ha destruido buena parte de las representaciones que en él se encuentran. Además se aprecian dos figuras piqueteadas de tiempos históricos. En esta zona hay que destacar, en la parte baja, la que para nosotros es la silueta más espectacular de todo el conjunto. Se trata de un protomos de caballo de $11,8 \mathrm{~cm}$ de longitud por $6,2 \mathrm{~cm}$ de anchura (figs. 13 y 14), mirando hacia la derecha. La imagen está rota en la parte inferior, faltándole las patas delanteras, todo el vientre y los cuartos traseros; únicamente conserva la parte anterior. El contorno está hecho con un trazo ligeramente más ancho, $1,5 \mathrm{~mm}$ y más profundo, $1 \mathrm{~mm}$, mientras que los trazos interiores son mucho más finos y someros. Junto al contorno, también se distingue en trazo grueso, el despiece de la crinera y otra estría perpendicular que discurre desde las orejas hasta la parte interior del pecho. En general, está realizado en trazo simple y único, aunque en algunas zonas se pueden ver algunas correcciones del surco definitivo. El morro presenta la clásica inflexión del belfo que marca también la quijada o babilla; en el interior hay tres trazos cortos que pueden representar el ollar (fig. 15). Toda la cabeza, así como la crinera, posee una serie de lineas que pudiera representar el pelaje. En la parte superior, se distingue bien una de las orejas, siendo el trazo que se aprecia detrás del pabellón auditivo, el 


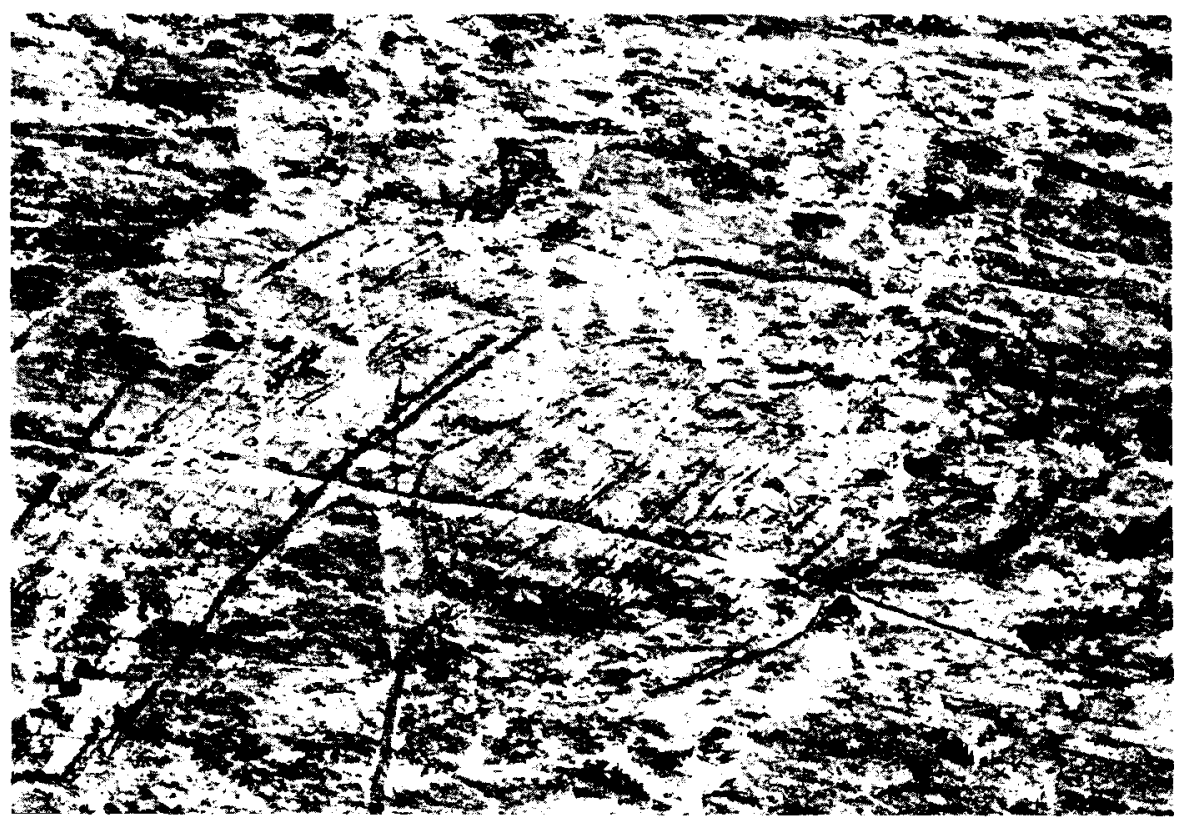

Fig. 15. Fotografia del detalle de la cabeza del caballo de la roca $37 e$

inicio de la nuca o tupé. La linea cervico-dorsal es uno de los puntos donde podemos ver el desdoblamiento del trazo, que es poco continuo cuando discurre paralelo.

Es una representación espléndida, cuyo encuadre paleolitico está totalmente fuera de duda. Sus semejanzas con algunas representaciones de équidos halladas en cavidades profundas, tanto de la cornisa Cantábrica como francesas, es evidente.

Por encima de esta magnifica figura, hemos localizado otra figuración de équido bastante incompleta $(36,2 \mathrm{~cm}$ de longitud por $22 \mathrm{~cm}$ de anchura) (fig. 13), que mira hacia la derecha. El graffiti moderno ha deteriorado bastante la integridad de los surcos, pero los existentes permiten un encuadre zoo técnico bastante correcto. Se aprecian muy bien los cuartos traseros, con una cola alzada, así como la parte del vientre y el inicio de la pata delantera que está perdida por el grabado piqueteado. La línea cervico-dorsal no existe y de una forma inconexa hallamos la cabeza en la que se conserva la quijada o babilla, el morro y la testuz. Este grabado está realizado en trazo fino y poco profundo. 


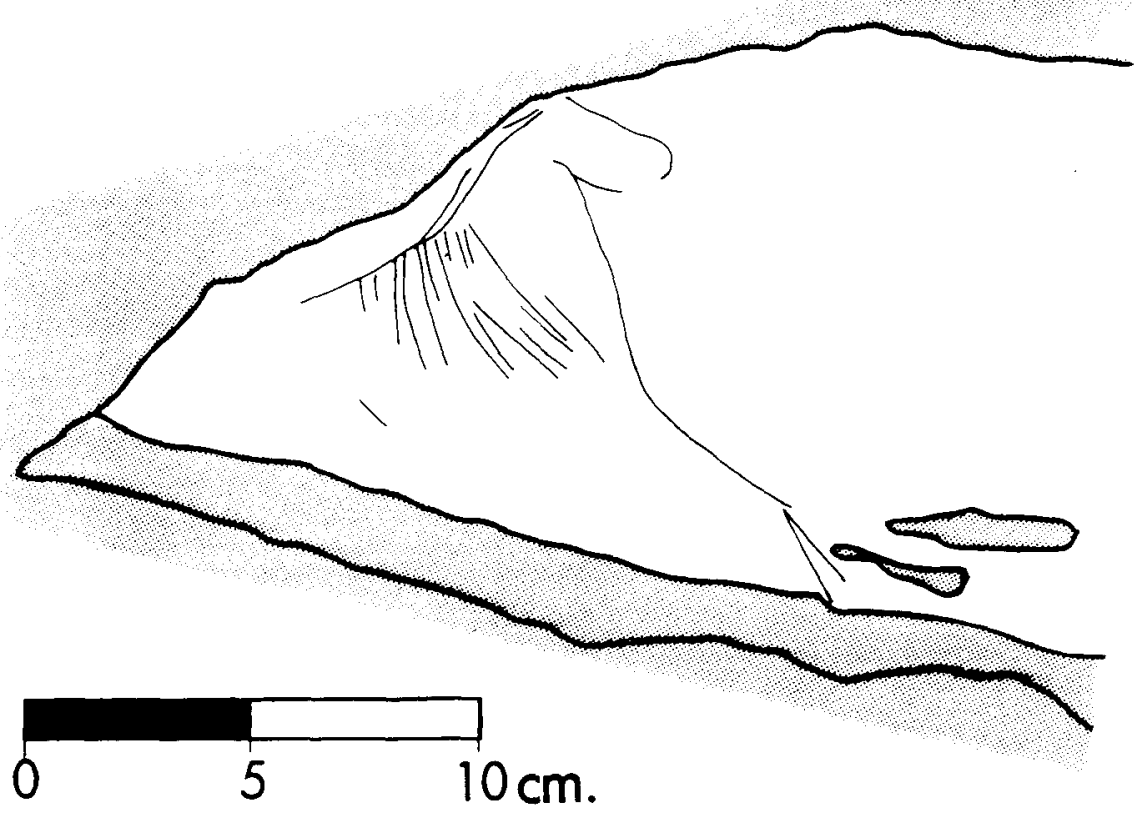

Fig. 16. Calco de la roca $37 e$ (izquierda)

En todo este panel hemos hallado otras lineas, pero dada la destrucción antrópica existente, no creemos posible identificar otras figuras.

Más hacia el Oeste, hemos descubierto otro protomos de caballo $(9,2 \mathrm{~cm}$ de longitud por $12,7 \mathrm{~cm}$ de anchura) (fig. 16), bastante esquemático, que mira hacia la derecha. La línea del pecho y la pata se prolongan hacia adelante como en actitud de correr. La cabeza y la crinera están bien definidas y en el interior del dorso se ven algunas estrias que posiblemente quieran representar el pelaje. Las exfoliaciones naturales han destruido una parte de esta figura.

ROCA 39

En el macizo 39, situado a media ladera, de grandes dimensiones, hemos localizado únicamente una representación paleolitica. Se trata de una cierva completa (13,9 cm de longitud por $10,4 \mathrm{~cm}$ de anchura) (fig. 17), 


\section{Las representaciones de estilo paleolitico en el conjunto de ...}
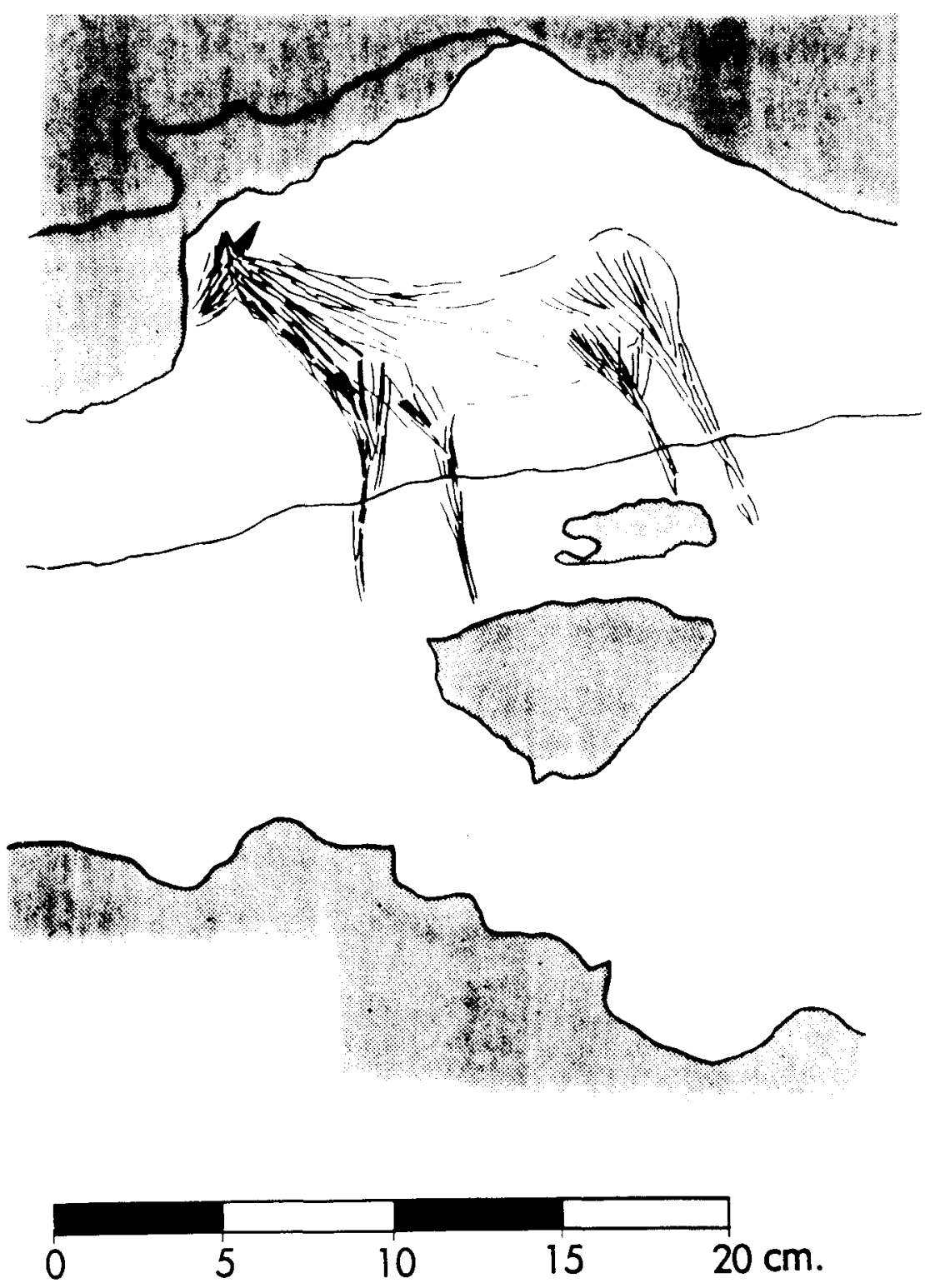

Fig. 17. Calco de la cierva de la roca 39 
que mira hacia la izquierda. Esta figura es de gran complejidad ya que está realizada mediante la técnica del trazo múltiple. Tanto la cabeza, orejas y el interior de la parte anterior y posterior del cuerpo está rellena de surcos más o menos paralelos que le dan un cierto volumen. La parte central del cuerpo posee menos incisiones, pero se puede apreciar bastante bien la linea cervico-dorsal y la ventral. Hasta ahora es la única figuración hallada en esta zona segoviana que posee estas características.

Las orejas están perfectamente identificadas en una perspectiva torcida, orientándose una de ellas hacia arriba y la otra hacia atrás. Las patas son bastante toscas y no representan las pezuñas.

\section{ZONA DE LAS CANTERAS}

La ampliación del área de prospección preliminar fue motivada fundamentalmente por la voladura de una roca, llevada a cabo en los trabajos de explotación de una de las canteras. Ello nos obligó a plantearnos

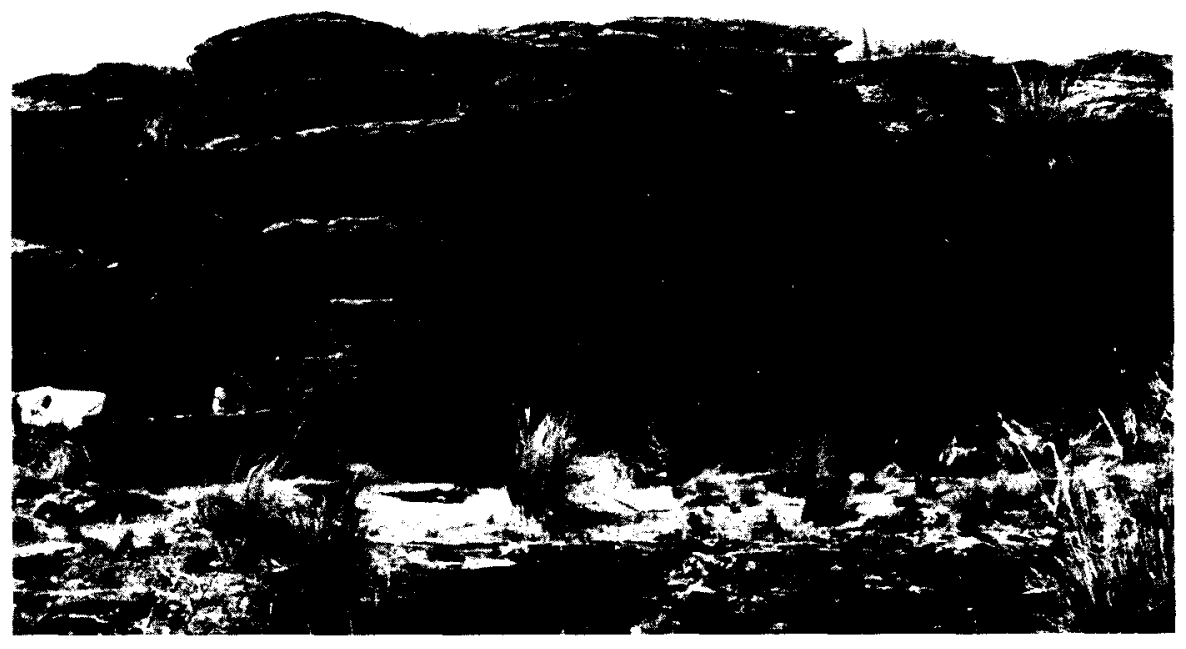

Fig. 18. Vista de conjunto del afloramiento de la zona de las canteras 
la necesidad de prospectar con urgencia este terreno y documentar la posible existencia de grabados paleolíticos. Asi fue como localizamos, sobre un afloramiento bastante extenso y orientado hacia el Sur, otro nuevo grupo de representaciones naturalistas paleoliticas.

El afloramiento presenta una franja de superficie pulida cuya amplitud varia desde escasos centimetros hasta casi medio metro. Precisamente es en este sector de mayor extensión, donde se sitúa un panel de gran complejidad ( $85 \mathrm{~cm}$ de longitud por 45 de anchura) (fig. 18), en el que hemos podido distinguir nueve figuras, además de numerosos trazos.

Iniciaremos la descripción de los grabados de la zona de las canteras a partir del sector más occidental, donde hallamos unos posibles cuartos traseros de un cuadrúpedo, que de momento simplemente incluimos en el apartado de trazos. Junto a éstos, aparecen otros que tampoco ayudan a configurar ninguna representación.

Más hacia la derecha y situado en una pequeña superficie aparece la figura de un équido ( $20 \mathrm{~cm}$ de longitud por $9,9 \mathrm{~cm}$ de anchura) (fig. 19), que mira hacia la izquierda. Presenta un cierto esquematismo, junto con una postura bastante forzada hacia adelante. Se aprecia bien la cabeza
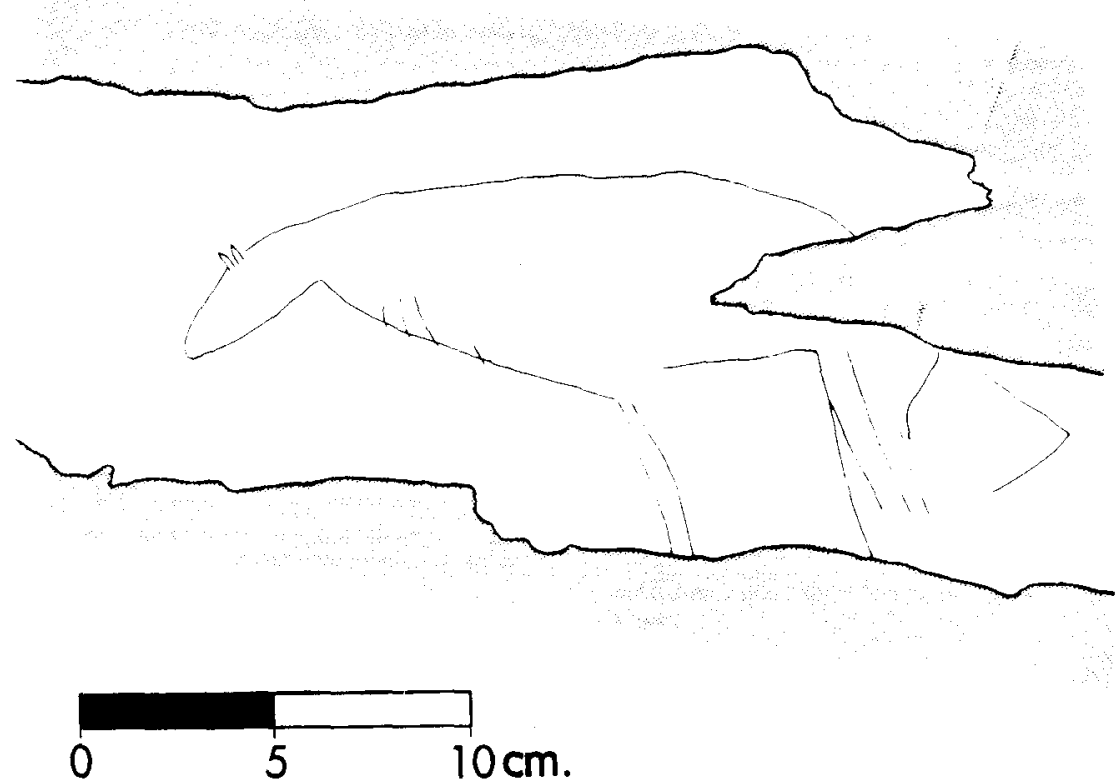

Fig. 19. Calco de la zona de las canteras (izquierda) 
con las dos orejas, asi como el resto del cuerpo salvo la parte de la grupa. Las extremidades resultan extrañas y no encajan dentro de los cánones de las figuras restantes.

Ligeramente más alto y hacia el Este encontramos el panel antes referido, donde llama poderosamente la atención una gran representación de cérvido cuyas dimensiones son $25,5 \mathrm{~cm}$ de longitud por $14,3 \mathrm{~cm}$ de anchura (fig. 20.1), mirando hacia la derecha. Es una representación espléndida que presenta una magnífica cabeza, pero a pesar de su magnificencia, plantea un cierto problema en la definición de su cornamenta. Si observamos la figura al completo, tiene las proporciones de una cierva hembra, sin embargo presenta un cuerno hacia adelante a modo de luchadera. Si por el contrario se tratase de un ciervo macho, es raro que sólo tenga esta cuerna hacia adelante y no posea el resto de las puntas, ya que en principio, la luchadera es una de las últimas en salir. A su vez y a continuación de esta cuerna, se aprecian cuatro trazos más paralelos que forman como otros dos cuernos hacia adelante y que terminan revolviéndose hacia atrás en forma de anzuelo. En un primer momento pensamos que estos apéndices formaban parte de la cornamenta del ciervo, creyendo incluso que pudiera tratarse de una gamuza o sarrio, pero un análisis detallado posterior, nos demostró que aquellos eran independientes del cérvido.

En el interior de la cabeza se distingue el ojo, de forma almendrada (fig. 21), y en la parte del hocico unos trazos que podrian simular la boca y el ollar. La parte superior del cuello, que parte de la oreja situada inmediatamente detrás de la cuerna, está realizada mediante una incisión discontinua -nueve líneas - hasta el punto en que se inicia el dorso, donde el trazo vuelve a ser simple y continuo.

Si magnifica es la cabeza, mucho más logrados son aún los cuartos traseros que poseen una especial gracilidad. La cola es corta y la pata trasera derecha, aparece curvada hacia atrás con una pezuña muy bien delimitada. La otra pata trasera, situada en un plano inferior para simular una perspectiva, está peor acabada y no se distingue la pezuña, rota sin duda por un desconchón. La linea del viente es prácticamente inexistente hasta el inicio de la pata delantera derecha, que junto con la izquierda - proyectada hacia adelante- tienen las características extremidades del conjunto que presentamos. Toda la figura está realizada con una incisión muy fina y somera, que en los cuartos traseros se hace ligeramente más gruesa y profunda.

Superponiéndose a la cabeza del cérvido, encontramos la cabeza de un cáprido completo (16,2 cm de longitud por $8,1 \mathrm{~cm}$ de anchura) (fig. 20.2), mirando hacia la izquierda. El morro de esta cabra se sitúa 


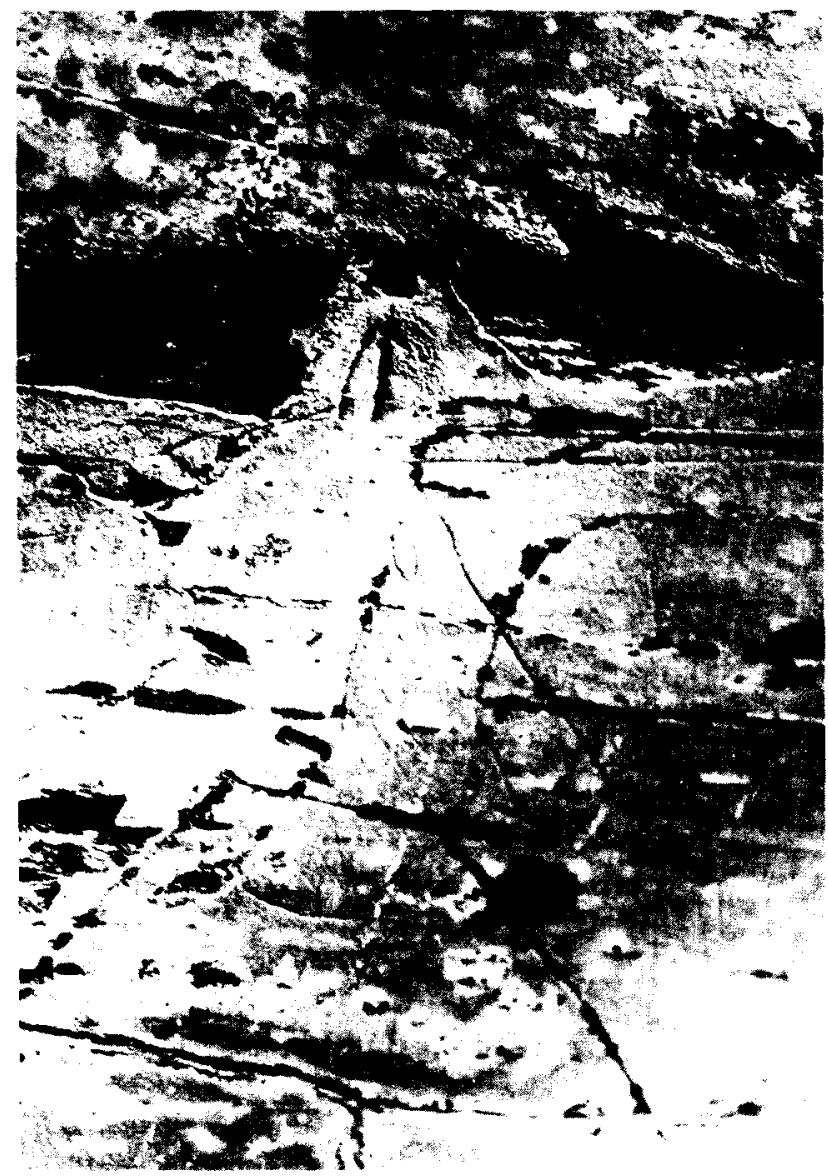

Fig. 21. Detalle de la cabeza del cérvido y cáprido del panel principal de la zona de las canteras

inmediatamente debajo de la quijada del cérvido; las cuernas atraviesan el interior de la cabeza y el ojo de aquella figura, saliendo al exterior por la parte de la testuz. Se distingue todo el contorno, siendo las extremidades bastante atipicas. Una de las patas anteriores está realizada mediante una forma subcuadrangular, mientras que las otras son simples trazos paralelos. En general, esta representación está hecha con un grabado bastante fino y poco profundo.

En la zona cervico-dorsal de este último cáprido hemos identificado los restos de una cabeza de caballo $(2,3 \mathrm{~cm}$ de longitud por $4,7 \mathrm{~cm}$ 
de anchura) (fig. 20.3), que mira hacia la izquierda. Las caracteristicas zoo técnicas de la cabeza nos inducen a clasificarlo como équido. Está realizada con un trazo muy fino y somero.

Al final de este gran panel, en la parte de la derecha bajo una gran cantidad de trazos paralelos antiguos y otros más recientes, se distingue otro protomos de cáprido $(8,4 \mathrm{~cm}$ de longitud por $4,8 \mathrm{~cm}$ de anchura) (fig. 20.4), mirando hacia la izquierda. Sigue el mismo esquema de realización que el resto de los cápridos. Los cuernos, ejecutados a base de dos simples trazos, son casi verticales en contraposición a otras figuras del mismo tipo que se distinguen en esta superficie, generalmente curvados hacia atrás. La parte inferior del cuerpo es inexistente por una exfoliación natural de la roca soporte.

Volviendo al centro del panel, en el interior del gran cérvido, se aprecia otra cabra casi completa $(11 \mathrm{~cm}$ de longitud por $7,3 \mathrm{~cm}$ de anchura) (fig. 20.5), mirando hacia la derecha. La cabeza está cortada por la línea cervico-dorsal de la figura que lo contiene y se encuentra en una posición ligeramente rampante con el cuerno delantero prolongado en un mismo trazo que forma la cabeza y el pecho. El morro es un poco curvo y la pata delantera está inacabada, pero por sus caracteristicas se completaría en dos surcos paralelos. Se observa asi mismo la línea del dorso y la grupa, perdiéndose las patas traseras y el vientre.

A la altura de la cola del cérvido, a la izquierda, hemos localizado otra figura de dificil identificación. Zoo técnicamente se trata de un protomos de caballo (2,9 cm de longitud por $3,8 \mathrm{~cm}$ de anchura) (fig. 20.6), mirando hacia la izquierda. El interior de la cabeza aparece relleno de trazos y se distingue el despiece de la crinera. Esta caracteristica de la cabeza nos ha llevado a buscarle paralelos en los équidos encontrados en Escoural (Portugal).

En la parte posterior del cérvido se aprecian una serie de surcos en los que a pesar de ser muy someros y fragmentarios, hemos podido identificar un protomos de caballo $(5 \mathrm{~cm}$ de longitud por $8,2 \mathrm{~cm}$ de anchura) (fig. 20.7), mirando hacia la izquierda y en actitud ligeramente rampante.

En la parte más amplia del panel, encima de este último équido y con las mismas caracteristicas del anterior en cuanto al tipo de trazo, se distingue un protomos de cierva $(14,7 \mathrm{~cm}$ de longitud por $18,5 \mathrm{~cm}$ de anchura) (fig. 20.8), orientada hacia la izquierda. Se puede ver con claridad la oreja enhiesta, la línea cervico-dorsal y la del pecho. Esta representación tiene una gran similitud con la que hemos descrito en el panel 15, orientación Sur.

Por último, y por encima de todas las figuras hasta ahora descritas en este complejo panel, hemos distinguido un gran cérvido $(36,7 \mathrm{~cm}$ de lon- 
gitud por $28,3 \mathrm{~cm}$ de anchura) (fig. 20.9), orientado hacia la derecha, al que le falta la cabeza desprendida en una exfoliación. El estudio de esta figura está aún pendiente de estudio ya que ha sido identificada al realizar los calcos.

Por último, hay que añadir que toda la superficie de este amplio panel, presenta un sinfín de trazos verticales, de escaso recorrido, sobre todas las figuras, en los que hasta la actualidad no hemos podido identificar otras representaciones naturalistas paleoliticas.

Más hacia el Este, a la misma altura que el anterior, se prolonga esta superficie "antigua" en la que hemos calcado numerosas lineas verticales, pero la fragmentación de la roca dificulta la identificación de otras figuraciones.

\section{GENERALIDADES SOBRE LAS REPRESENTACIONES}

A continuación vamos a intentar sintetizar los rasgos fundamentales de este nuevo conjunto figurativo al aire libre de Domingo Garcia.

1. Casi la totalidad de las representaciones presenta una orientación Sur o Sureste, salvo alguna excepción situada hacia el Oeste y Este. En ningún caso, por el momento, hemos localizado figuras orientadas hacia el Norte, lo que puede deberse a la gran erosión eólica de las superficies orientadas en esa dirección. Por otra parte, es en estos frentes donde existe una mayor profusión de liquenes incrementando asi el proceso erosivo de la superficie rocosa.

2. Todas las figuras han sido realizadas sobre la superficie friada * —antigua - no habiéndose apreciado grabados de trazo fino sobre las superficies que se crean a posteriori.

3. El trazo es simple - a excepción del caso de la cierva de la roca 39 , que es múltiple-, sumamente fino y en general muy poco profundo, variando entre 0,5 y $1 \mathrm{~mm}$. Todos ellos tienen la misma pátina que el soporte, menos la cabra del panel oblicuo de la roca 15 , que es un poco más clara.

4. La mayoría de las representaciones se muestran en una posición estática, como suspendidas en el aire. Raras son las figuras que intentan reflejar un movimiento, como puede ser el caso del caballo de la roca 37 e, el bóvido del panel superior de la roca 12, o el gran cérvido de la zona de las canteras.

\footnotetext{
- Esta adscripción está pendiente de un análisis geológico detallado de las superficies
} 
5. En general, el cuerno y la cabeza de bastantes figuras, están realizados con el mismo trazo, apreciándose en el caso de los cápridos, una zona sin incisión entre los dos cuernos.

6. Las figuras aparecen siempre de perfil y sobre una serie de 34 representaciones perfectamente identificadas observamos que un 35,29 por 100 , miran hacia la derecha, frente a una clara mayoria que mira a la izquierda, alcanzando un 64,70 por 100. Si atendemos a las especies, hay que señalar que todos los bóvidos (3) miran hacia la izquierda, mientras que los cápridos (6) se reparten al 50 por 100. En cuanto a los équidos (15), sigue predominando la izquierda $(66,66$ por 100) frente a la derecha $(33,33$ por 100$)$. Algo similar ocurre con los cérvidos (10) de los que un 60 por 100 mira hacia la izquierda, frente a un 40 por 100 que mira hacia la derecha.

7. El conjunto presenta una cierta unidad crono-cultural, que a falta de más datos podemos encuadrar genéricamente en un Solutrense Superior Final o bien en un Magdaleniense Inicial. Los motivos que nos llevan a proponer esta cronologia están determinados por las características convenciones estilísticas observadas en determinadas figuras. Las representaciones solutrenses, que son la mayoría, presentan el morro y belfo ligeramente en forma de "pico de pato" en el caso de los caballos; la cabeza y el cuerno delantero de los cápridos están realizados mediante un único trazo, estando ausente el que uniria los dos cuernos. Algunos de los despieces interiores como pueden ser las crineras o las lineas ventrales aparecen también en algunas plaquetas solutrenses de la cueva del Parpalló (PERICOT, L. 1942). Sin embargo, son las extremidades - todas ellas acabadas en sendos trazos más o menos paralelos - las que nos circunscriben la atribución cultural solutrense.

Otras figuras presentan algunas convenciones que podemos considerar más avanzadas - quizás magdalenienses-. Tal es el caso de la cierva de la roca 39 con trazos múltiples, muy similares a los de los omoplatos de la cueva del Castillo (Almagro BASCH, M. 1976) y Altamira (CARTAIL.HAC, E. y BREUIL, H. 1906); o el protomos de caballo de la roca 37 que también contiene algunos trazos múltiples tal y como podemos ver en otras representaciones parietales de la cornisa cantábrica.

Queremos dedicar el presente artículo a la memoria de nuestro gran amigo Fernando Piñón Varela en el cuarto aniversario de su fallecimiento. Estamos seguros que de seguir vivo firmaria este artículo con nosotros. 


\section{BIBLIOGRAFIA}

Almagro Basch. M., Los omoplatos decorados de la cueva de El Castillo. Puente Viesgo (Santander). Monografias Arqueológicas n." 2. 1976. Museo Arqueológico Nacional. 99 págs. 76 figs. y XII láminas

Balbin Behrmann, R. de: Moure Romanillo, J. A. (1988): "El arte rupestre en Domingo Garciáa (Segovia)". Revista de Arqueología, 87. págs. 16-24

Bal bin Behrmann. R. de: Moure Romanil lo. J. A. y Ripoll Perello. E. (1982): "Grabados esquemáticos de la comarca de Santa Maria de Nieva (Segovia)», Coloquio Internacional sobre el Arte Rupestre Esquemático de la Peninsula Ibérica. Resumen de Comunicaciones. Salamanca. págs. 8 y 9 .

Balbin Behrmann. R. de: Alcolen Gonzalez, J.: Santonja. M.. y Perrez Martin. R. (1991): "Siega Verde (Salamanca). Yacimiento artístico paleolitico al aire libre". Del Paleolitico a la Historia. Museo de Salamanca. págs. 33-48, 12 figs.

Carthtallhac, E. y Breull. H. La Caverne de Altamira a Santillane prés Santander (Espagne). Peintures et gravures murales des cavernes paléolithiques. Mónaco 1906, 287 págs.. 204 figs. Y XXXVII láminas.

Corchon. S: Lucas, R.: GonzAlfz-Tablas. F. y Becares, J. (1991): "El arte rupestre prehistórico en la región castellano-leonesa (España)». Zephyrus, XLI-XLII. Salamanca, págs. 7-18.

Gozalo Quintanilla. F. (1970): "Arte rupestre en la provincia de Segovia". Revista Ejército, 370, págs. 5-9.

Lucas Pellicer. R. (1971): "Grabados rupestres en la comarca de Santa María de Nieva" Estudios Segovianos, vol. 67. Segovia, págs. 132-140

- (1973): "Grabados rupestres en Domingo Garcia". XIII Congreso Nacional de Arqueologia. Zaragoza, págs. 257-266.

- (1974): "El arte rupestre en la provincia de Segovia". Cuadernos de Prehistoria y arqueologia de la Universidad Autonoma, I. Madrid, págs. 57-69.

Martin Santamaria, E.; Moure Romanillo, J. A. (1981): "El caballo de estilo paleolítico de Domingo Garcia”. Trabajos de Prehistoria, vol. 38. Madrid. págs. 97-108.

Pericot Garcia, L., "La cueva del Parpalló (Gandia)". Consejo Superior de Investigaciones Cientificas, Instituto Diego Velázquez. Madrid, 1942, 349 págs. 650 figs. y XXXII láminas

Tuñón Mallada. P. (1929): "Estilizaciones rupestres ibéricas". Actas y Memorias de la Sociedad española de Arqueologia, Etnologia y Prehistoria. T. VIII, págs. 9-11. 